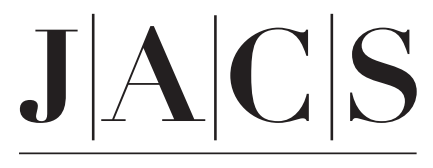

A R T I C L E S

Published on Web 04/06/2002

\title{
A Comprehensive Investigation of the Chemistry and Basicity of a Parent Amidoruthenium Complex
}

\author{
J. Robin Fulton, Stepan Sklenak, Marco W. Bouwkamp, and Robert G. Bergman* \\ Contribution from the Department of Chemistry and the Center for New Directions in Synthesis \\ (CNDOS), University of California, Berkeley, California 94720
}

Received August 2, 2001

\begin{abstract}
DMPE) ${ }_{2} \mathrm{Ru}(\mathrm{H})\left(\mathrm{NH}_{2}\right)($ 1) dehydrogenates cyclohexadiene and 9,10-dihydroanthracene to yield benzene (or anthracene), (DMPE) $)_{2} \mathrm{Ru}(\mathrm{H})_{2}$, and ammonia. Addition of fluorene to 1 results in the formation of the ion pair [trans-(DMPE) $\left.)_{2} \mathrm{Ru}(\mathrm{H})\left(\mathrm{NH}_{3}\right)^{+}\right]\left[\mathrm{A}^{-}\right]\left(\mathrm{A}^{-}=\right.$fluorenide, 4a). Complex 1 also reacts with weak acids $\mathrm{A}-\mathrm{H}(\mathrm{A}-\mathrm{H}=$ phenylacetylene, 1,2-propadiene, phenylacetonitrile, 4-( $\alpha, \alpha, \alpha$-trifluoromethyl)phenylacetonitrile, cyclobutanone, phenol, $p$-cresol, aniline) to form ammonia and trans-(DMPE $)_{2} R u(H)(A)$ $(7,8,9 a, 9 b, 10,11 b, 11 c, 12$, respectively). In the cases where $A-H=$ phenylacetylene, cyclobutanone, aniline, phenol, and $p$-cresol, the reaction was observed to proceed via ion pairs analogous to $\mathbf{4 a}$. Compound $\mathbf{1}$ is reactive toward even weaker acids such as toluene, propylene, ammonia, cycloheptatriene, and dihydrogen, but in these cases deuterium labeling studies revealed that only $H / D$ exchange between $A-H$ and the $\mathrm{ND}_{2}$ group is observed, rather than detectable formation of ion pairs or displacement products. Addition of triphenylmethane to 1 results in the formation of an equilibrium mixture of $\mathbf{1}$, triphenylmethane, and the ruthenium/triphenylmethide ion pair $\mathbf{4 h}$. If the energetics of ion-pair association are ignored, this result indicates that the basicity of $\mathbf{1}$ is similar to that of triphenylmethide. All these observations support the conclusion that the $\mathrm{NH}_{2}$ group in amido complex $\mathbf{1}$ is exceptionally basic and as a result prefers to abstract a proton rather than a hydrogen atom from a reactive $\mathrm{C}-\mathrm{H}$ bond. The energetics and mechanism of these proton-transfer and -exchange reactions are analyzed with the help of DFT calculations.
\end{abstract}

\section{Introduction}

Late transition metal complexes containing nondative metaloxygen or - nitrogen single bonds (for brevity, defined here as "M-X" bonds) serve many different roles in biological systems and have been implicated as intermediates in several industrially important catalytic reactions. ${ }^{1-3}$ However, the nature of the $\mathrm{M}-\mathrm{O}$ (alkoxo, hydroxo) and $\mathrm{M}-\mathrm{N}$ (amido) bonds is not completely understood. Some of these complexes exhibit the ability to abstract a hydrogen atom from a weak $\mathrm{C}-\mathrm{H}$ bond, suggesting that the metal-heteroatom bond can participate in homolytic reactions. ${ }^{4-6}$ For example, Stack and co-workers prepared $\left[\mathrm{Fe}^{\mathrm{III}}(\mathrm{PY} 5)(\mathrm{OMe})\right][\mathrm{OTf}]_{2}(\mathrm{PY} 5=2,6$-bis $((2$-pyridyl)methoxymethane)pyridine $)^{4}$ as a model for lipoxygenase ${ }^{7-13}$ and

* To whom correspondence should be addressed. E-mail: bergman@ cchem.berkeley.edu.

(1) Bryndza, H. E.; Tam, W. Chem. Rev. 1988, 88, 1163

(2) Roundhill, D. M. Chem. Rev. 1992, 92, 1.

(3) Holm, R. H.; Kennepohl, P.; Solomon, E. I. Chem. Rev. 1996, 96, 2239.

(4) Jonas, R. T.; Stack, T. D. P. J. Am. Chem. Soc. 1997, 119, 8566.

(5) Mayer, J. M. Acc. Chem. Res. 1998, 31, 441.

(6) Lockwood, M. A.; Wang, K.; Mayer, J. M. J. Am. Chem. Soc. 1999, 121, 11894.

(7) Samuelsson, B.; Dahlén, S.-E.; Lindgren, J. A.; Rouzer, C. A.; Serhan, C. N. Science 1987, 237, 1171.

(8) Glickman, M. H.; Wiseman, J. S.; Klinman, J. P. J. Am. Chem. Soc. 1994, 116, 793.

(9) Nelson, M. J.; Cowling, R. A.; Seitz, S. P. Biochemistry 1994, 33, 4966.

(10) Nelson, M. J.; Seitz, S. P.; Cowling, R. A. Biochemistry 1990, 29, 6897.

(11) Moiseyev, N.; Rucker, J.; Glickman, M. H. J. Am. Chem. Soc. 1997, 119 , 3854.

(12) Ogo, S.; Wada, S.; Watanabe, Y.; Iwase, M.; Wada, A.; Garata, M.; Jitsukawa, K.; Masuda, H.; Einaga, H. Angew. Chem., Int. Ed. 1998, 37, 2102 .

722 a J. AM. CHEM. SOC. 2002, 124, 4722-4737

have shown that it readily oxidizes cyclohexadiene (CHD) to benzene and the corresponding $\mathrm{Fe}^{2+}-\mathrm{MeOH}$ complex. This reaction is proposed to proceed by initial $\mathrm{H}$-atom abstraction by the $\mathrm{Fe}-\mathrm{OMe}$ group to give an intermediate cyclohexadienyl radical.

However, direct observation of this type of odd electron reactivity in simple $\mathrm{M}-\mathrm{X}$ complexes appears to be rare and may depend on the possibility of a favorable change in the oxidation state of the metal. Most late metal amido and alkoxo $\mathrm{M}-\mathrm{X}$ complexes exhibit reactivity consistent with a strongly polarized $\mathrm{M}-\mathrm{X}$ bond, sometimes to the extent that the reactivity of the heteroatom is analogous to that of an alkali metal salt. ${ }^{1,14}$ Despite this, there is little evidence for direct ionization of $\mathrm{M}-\mathrm{X}$ bonds, and in some systems there is strong evidence that the heteroatom is tightly bound to the metal center. ${ }^{15}$ Recent quantitative equilibrium studies by our group, ${ }^{16,17}$ in combination with earlier studies by Bryndza and Bercaw, ${ }^{18}$ have concluded that the heteroatom ligands that are better able to stabilize a negative charge form significantly stronger $\mathrm{M}-\mathrm{X}$ bonds than

(13) Clapp, C. H.; Senchak, S. E.; Stover, T. J.; Potter, T. C.; Findeis, P. M.; Novak, M. J. J. Am. Chem. Soc. 2001, 123, 747.

(14) Caulton, K. G. New J. Chem. 1994, 18, 25.

(15) Simpson, R. D.; Bergman, R. G. Organometallics 1993, 12, 781.

(16) Holland, P. L.; Andersen, R. A.; Bergman, R. G.; Huang, J.; Nolan, S. P. J. Am. Chem. Soc. 1997, 119, 12800.

(17) Holland, P. L.; Andersen, R. A.; Bergman, R. G. Comments Inorg. Chem. 1999, 21, 115 .

(18) Bryndza, H. E.; Fong, L. K.; Paciello, R. A.; Tam, W.; Bercaw, J. E. J. Am. Chem. Soc. 1987, 109, 1444.

10.1021/ja011876o CCC: \$22.00 @ 2002 American Chemical Society 
those which do not have this ability. This provides further evidence for the significant polar nature of these complexes.

We recently reported the synthesis of trans-(DMPE) ${ }_{2} \mathrm{Ru}(\mathrm{H})$ $\left(\mathrm{NH}_{2}\right)(\mathbf{1})\left(\mathrm{DMPE}=1\right.$,2-dimethylphosphinoethane).${ }^{19}$ Complex $\mathbf{1}$ is the first isolable monomeric structurally characterized latemetal parent amido complex. The handful of known monomeric parent amido complexes exhibit nucleophilic behavior; ${ }^{20-22}$ however, the instability of these complexes, and/or the impure reaction mixtures in which they are generated, has prevented a thorough study of their properties. Most known monomeric late metal amido complexes are anilido based and are therefore stabilized by electronic delocalization into the $\pi$-system of the aryl ring. ${ }^{17,23-27}$ Our monomeric parent amido complex 1 lacks this added stabilization, providing us with an opportunity to directly study the unperturbed metal-nitrogen bond. This paper describes studies that provide evidence that is consistent with $2 \mathrm{e}^{-}$chemistry in this system and suggest that the highly polar nature of the $\mathrm{Ru}-\mathrm{N}$ bond dictates the reactivity of this molecule.

\section{Results}

Reaction of trans-(DMPE $)_{2} \mathbf{R u}(\mathbf{H})\left(\mathbf{N H}_{2}\right)$ with Cyclohexadiene and 9,10-Dihydroanthracene. Treatment of the ruthenium amido complex 1 with 1,4-cyclohexadiene (1,4-CHD) in THF- $d_{8}$ (eq 1) produces benzene in greater than $95 \%$ yield as observed by ${ }^{1} \mathrm{H}$ NMR spectroscopy. The coproduct was not a $\mathrm{Ru}-\mathrm{NH}_{3}$ complex, but instead was a mixture of the known $(\mathrm{DMPE})_{2} \mathrm{Ru}(\mathrm{H})_{2}(3)$ and free ammonia, both in $>95 \%$ yield. ${ }^{28}$ Thus, in analogy to Stack's system, 1 oxidizes 1,4-CHD to benzene. However, in contrast to Stack's system, the formal oxidation state of the metal does not change. ${ }^{4}$

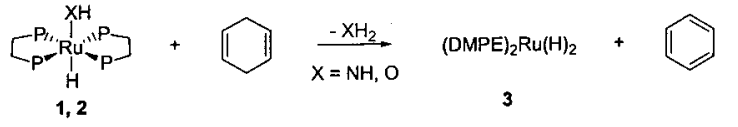

A similar, albeit slower, reaction was observed when hydroxo complex 2 was used as the oxidant. Water was presumably formed instead of ammonia, although no resonances corresponding to water could be found. In a similar fashion, both amido complex 1 and hydroxo complex 2 oxidize 9,10dihydroanthracene (DHA) to anthracene (eq 2) in greater than 95\% yield. However, compounds $\mathbf{1}$ and $\mathbf{2}$ also catalyze (more rapidly) the interconversion of $1,4-$ and $1,3-\mathrm{CHD}\left(t_{1 / 2}<5 \mathrm{~min}\right)$ prior to dehydrogenation (eq 3 ), a process not reported in the Stack system.

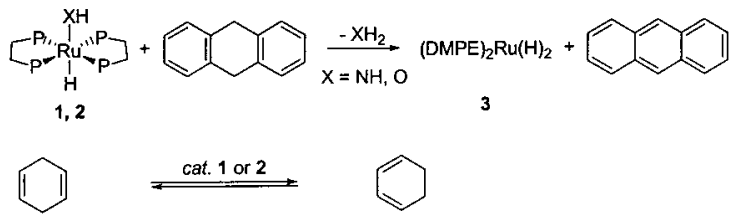

Among several possible mechanisms, these processes could in principle occur by initial abstraction of either a hydrogen

(19) Kaplan, A. W.; Ritter, J. C. M.; Bergman, R. G. J. Am. Chem. Soc. 1998, $120,6828$.

(20) Dewey, M. A.; Knight, D. A.; Gladysz, J. A. Chem. Ber. 1992, 125, 815

(21) Joslin, F. L.; Johnson, M. P.; Mague, J. T.; Roundhill, D. M. Organome tallics 1991, 10, 2781

(22) Tahmassebi, S. K.; McNeil, W. S.; Mayer, J. M. Organometallics 1997, 16, 5342.

(23) Casalnuovo, A. L.; Calabrese, J. C.; Milstein, D. J. Am. Chem. Soc. 1988 110,6738 .
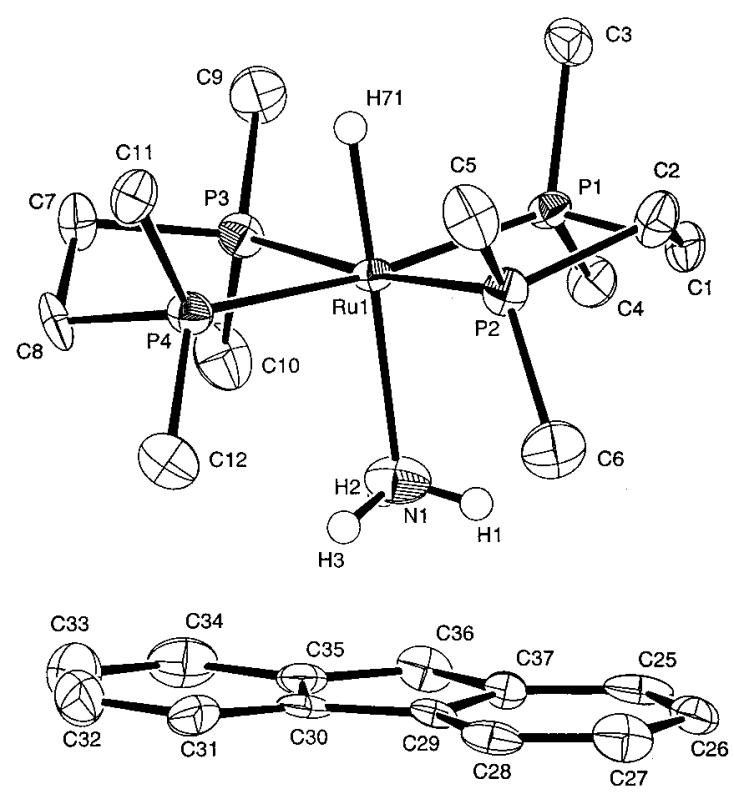

Figure 1. ORTEP diagram of $\mathbf{4 a}$.

Scheme 1

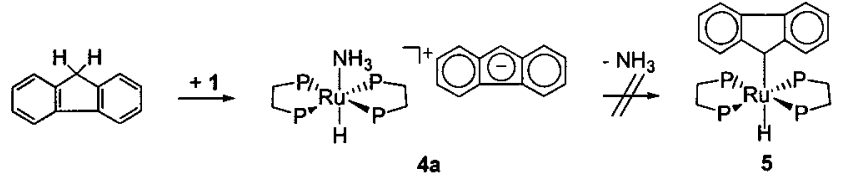

atom or a proton (vide infra). To explore this question, we extended the above investigation to a series of organic compounds having $\mathrm{C}-\mathrm{H}$ bonds characterized by a wide range of bond dissociation energies and acidities.

Deprotonation of Fluorene by Amido Complex 1 and Hydroxo Complex 2: Formation of Ion Pairs. Ammoniabound complex $\mathbf{4 a}$ was formed in $90 \%$ yield upon treatment of amido complex 1 with fluorene in THF (Scheme 1). The ${ }^{1} \mathrm{H}$ NMR spectrum of this material shows coordinated ammonia proton signals at $\delta-0.6$ and the bridgehead proton on the fluorenide anion at $\delta 5.94$.

Consistent with the proposed ionic structure, this complex is sparingly soluble in aromatic solvents and insoluble in aliphatic solvents. Crystals suitable for an X-ray diffraction study were obtained by slow diffusion of pentane into a THF solution of 4a in THF at $-30^{\circ} \mathrm{C}$. An ORTEP diagram is shown in Figure 1. Crystal and data collection parameters are given in Table 1, and selected intramolecular distances and bond angles are given in Table 2. The crystal structure confirms the presence of a coordinated ammonia ligand. The $\mathrm{Ru}-\mathrm{N}$ bond distance is $2.252-$ (7) $\AA$, longer than the $\mathrm{Ru}-\mathrm{N}$ bond distance of the parent complex (2.191(6) ^). The distance between the fluorenide plane and the nitrogen atom of the coordinated ammonia ligand is $3.00 \AA$.

(24) (a) Bergman, R. G. Polyhedron 1995, 14, 3227. (b) Fulton, J. R.; Holland A. W.; Fox, D. J.; Bergman, R. G. Acc. Chem. Res. 2002, 35, 44. (c) Some of the results described here were reported earlier in preliminary form: Fulton, J. R.; Bouwkamp, M. W.; Bergman, R. G. J. Am. Chem. Soc. 2000, $122,8799$.

(25) Martin, G. C.; Palenik, G. J.; Boncella, J. M. Inorg. Chem. 1990, 29, 2027

(26) Cowan, R. L.; Trogler, W. C. Organometallics 1987, 6, 2451

(27) Li, J. J.; Li, W.; James, A. J.; Holbert, T.; Sharp, T.; Sharp, P. R. Inorg. Chem. 1999, 38, 1563.

(28) Dihydride complex 3 exists as an equilibrium mixture of cis and trans isomers in solution, see: Field, L. D.; Hambley, T. W.; Yau, B. C. K. Inorg. Chem. 1994, 33, 2010. 
Table 1. Crystallographic Data for $4 a, 9 b, 10$, and $4 e$

\begin{tabular}{|c|c|c|c|c|}
\hline & $4 a$ & $9 b$ & 10 & $4 e$ \\
\hline empirical formula & $\mathrm{RuP}_{4} \mathrm{NC}_{29} \mathrm{H}_{53}$ & $\mathrm{RuP}_{4} \mathrm{~F}_{3} \mathrm{NC}_{21} \mathrm{H}_{38}$ & $\mathrm{RuP}_{4} \mathrm{OC}_{16} \mathrm{H}_{38}$ & $\mathrm{RuP}_{4} \mathrm{O}_{1.41} \mathrm{NC}_{21.71} \mathrm{H}_{43}$ \\
\hline & 656.71 & 586.5 & 471.44 & 565.63 \\
\hline crystal system & monoclinic & orthorhombic & triclinic & monoclinic \\
\hline$a(\AA)$ & $17.5506(3)$ & $18.00(2)$ & $9.3817(2)$ & $22.1659(1)$ \\
\hline$b(\AA)$ & $9.2847(2)$ & $12.5999(14)$ & $15.8315(3)$ & $11.6666(1)$ \\
\hline$c(\AA)$ & $35.0153(7)$ & $11.6542(13)$ & $16.5172(2)$ & $32.4664(2)$ \\
\hline$\alpha(\mathrm{deg})$ & & & $117.042(1)$ & \\
\hline$\beta$ (deg) & $91.7570(10)$ & & $90.520(1)$ & $106.977(1)$ \\
\hline$\gamma(\operatorname{deg})$ & & & 89.994(1) & \\
\hline$V\left(\AA^{3}\right)$ & $5703.13(17)$ & 2643.1(4) & $2184.92(7)$ & $5803.98(8)$ \\
\hline space group & $P(2)_{1} / a($ No. 14$)$ & Pnma (No. 62) & $\bar{P} 1$ (No. 2 ) & $P(2)_{1} / a($ No. 14$)$ \\
\hline$Z$ & 8 & 4 & 4 & 8 \\
\hline$D_{\text {calc }} \mathrm{g} / \mathrm{cm}^{3}$ & 1.530 & 1.474 & 1.433 & 1.295 \\
\hline$F_{\text {ооо }}$ & 2768.00 & 1208.00 & 984.00 & 2364.32 \\
\hline$\mu(\mathrm{Mo} \mathrm{K} \alpha) \mathrm{cm}^{-1}$ & 7.99 & 8.66 & 50.63 & 7.75 \\
\hline $2 \theta_{\max }$ & $52.5^{\circ}$ & $52.1^{\circ}$ & 52.2 & $49.4^{\circ}$ \\
\hline residuals: $R ; R_{\mathrm{w}} ; R_{\text {all }}$ & $0.043 ; 0.045 ; 0.134$ & $0.049 ; 0.052 ; 0.157$ & $0.029 ; 0.035 ; 0.041$ & $0.028 ; 0.028 ; 0.075$ \\
\hline GOF indicator & 0.98 & 1.47 & 1.59 & 0.88 \\
\hline
\end{tabular}

Table 2. Selected Intermolecular Distances $(\AA \AA)$ and Angles (deg) for $4 a, 4 e, 9 b$, and 10

\begin{tabular}{|c|c|c|c|c|}
\hline $4 a$ & $\begin{array}{l}\mathrm{Ru}-\mathrm{P}(\mathrm{av}) \\
\mathrm{Ru}-\mathrm{N} 1 \\
\mathrm{~N} 1 \cdots \text { fluorenide } \\
\text { plane }\end{array}$ & $\begin{array}{l}2.230 \\
2.252(7) \\
3.00\end{array}$ & $\mathrm{P}-\mathrm{Ru}-\mathrm{N} 1$ (av) & 93.3 \\
\hline $4 e$ & $\begin{array}{l}\mathrm{Ru}-\mathrm{P} \text { (av) } \\
\mathrm{Ru}-\mathrm{N} \text { (av) } \\
\mathrm{O} \cdots \mathrm{N} \text { (av) } \\
\mathrm{O}-\mathrm{C}_{\text {arvl }} \text { (av) }\end{array}$ & $\begin{array}{l}2.297 \\
2.251) \\
2.932 \\
1.305\end{array}$ & $\mathrm{P}-\mathrm{Ru}-\mathrm{N} 1(\mathrm{av})$ & 93.1 \\
\hline $9 b$ & $\begin{array}{l}\mathrm{Ru}-\mathrm{N} 1 \\
\mathrm{~N} 1-\mathrm{C} 1\end{array}$ & $\begin{array}{l}2.13(2) \\
1.18(2)\end{array}$ & $\mathrm{Ru}-\mathrm{N} 1-\mathrm{C} 1$ & $171(2)$ \\
\hline 10 & $\begin{array}{l}\mathrm{Ru}-\mathrm{P} \text { (av) } \\
\mathrm{Ru}-\mathrm{C} 13 \\
\mathrm{C} 13-\mathrm{C} 14 \\
\text { C13-C16 } \\
\text { C14-C15 } \\
\text { C15-C16 } \\
\text { C16-O1 }\end{array}$ & $\begin{array}{l}2.303 \\
2.338(3) \\
1.546(5) \\
1.451(5) \\
1.556(5) \\
1.527(5) \\
1.218(4)\end{array}$ & $\begin{array}{l}\mathrm{P}-\mathrm{Ru}-\mathrm{C} 13 \text { (av) } \\
\mathrm{Ru}-\mathrm{C} 13-\mathrm{C} 14 \\
\mathrm{Ru}-\mathrm{C} 13-\mathrm{C} 16 \\
\mathrm{C} 14-\mathrm{C} 13-\mathrm{C} 16 \\
\mathrm{C} 13-\mathrm{C} 14-\mathrm{C} 15 \\
\text { C14-C16-C16 } \\
\text { C13-C16-C16 } \\
\text { O1-C16-C13 } \\
\text { O1-C16-C15 }\end{array}$ & $\begin{array}{c}94.9 \\
119.0(2) \\
112.6(2) \\
89.9(3) \\
88.3(2) \\
86.8(3) \\
92.9(3) \\
136.7(3) \\
130.3(3)\end{array}$ \\
\hline
\end{tabular}

In the UV-vis spectrum, the $\lambda_{\max }$ of $\mathbf{4 a}$ in a dilute THF solution is $368 \mathrm{~nm}$, similar to that of the fluorenide-tetrabutylammonium ion pair. ${ }^{29}$ Displacement of ammonia from $4 \mathbf{a}$ to generate a covalent ruthenium-fluorenide complex 5 was not observed, even on prolonged heating (Scheme 1).

Treatment of the hydroxo complex 2 with fluorene results in the formation of an equilibrium mixture of $\mathbf{2}$, fluorene, and the aquo-fluorenide complex $\mathbf{6 a}$ (eq 4). The aromatic resonances in the ${ }^{1} \mathrm{H}$ NMR spectrum in THF- $d_{8}$ at $25{ }^{\circ} \mathrm{C}$ are broad, indicating the presence of a relatively fast exchange process occurring on the NMR time scale. Two hydride resonances corresponding to the hydroxo complex $2(\delta-21.4)$ and the aquo-fluorenide salt complex $\mathbf{6 a}(\delta-20.7)$ are observed. Upon cooling the reaction mixture, both hydride resonances shift to higher field, and the hydride resonance corresponding to hydroxo complex 2 decreases in intensity such that at $-80{ }^{\circ} \mathrm{C}$, the only hydride resonance present in the ${ }^{1} \mathrm{H}$ NMR spectrum corresponds to $\mathbf{6 a}(\delta-23.4)$. In addition to this resonance, four distinct aryl resonances and a new singlet at $\delta 5.97$ are present. These data are consistent with a shift in the equilibrium to favor $\mathbf{6 a}$ at lower temperatures. Repeated attempts to isolate this complex failed.

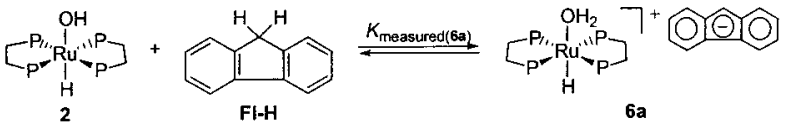

Scheme 2

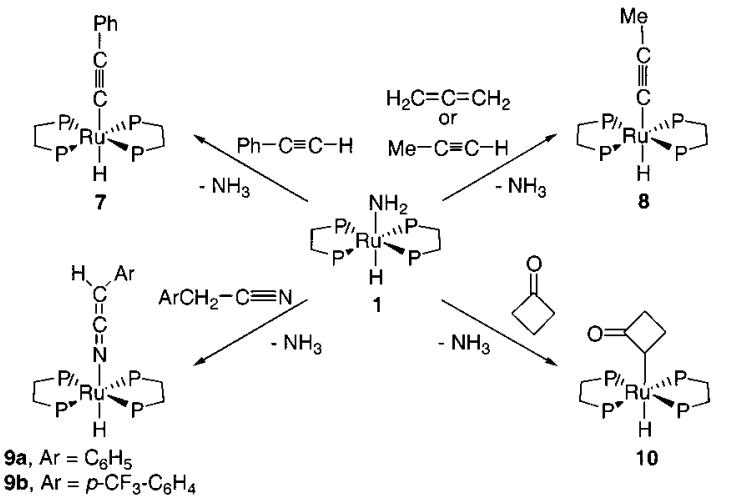

Reaction of Amido Complex 1 with Weak Acids: Displacement of Ammonia. Treatment of amido complex $\mathbf{1}$ with phenylacetylene results in the loss of ammonia and formation of the phenyl-acetylide complex 7 in greater than $95 \%$ yield (Scheme 2). This is analogous to the earlier-reported reaction that gives compound $\mathbf{7}$ when hydroxo complex $\mathbf{2}$ is treated with phenylacetylene. ${ }^{30}$ Addition of 1,2-propadiene to amido complex 1 results in loss of ammonia and a net 1,3-hydrogen shift to yield ruthenium methylacetylide complex $\mathbf{8}$ in $73 \%$ yield after 2 days at room temperature in toluene (Scheme 2). Complex 8 can be synthesized independently by treating 1 with propyne. Intriguingly, the rates of reaction of $\mathbf{1}$ with propyne and 1,2propadiene are not significantly different.

Complex $\mathbf{1}$ also functions as a prototropic isomerization catalyst in this system: addition of an excess of either 1,2propadiene or propyne to the amido complex 1 results in the interconversion of the two organic species to an equilibrium ratio of 1:4 (1,2-propadiene:propyne, eq 5). No prototropic isomerization is observed when 1,2-propadiene is added to a solution of methylacetylide complex $\mathbf{8}$.

$\mathrm{H}_{2} \mathrm{C}=\mathrm{C}=\mathrm{CH}_{2} \rightleftharpoons$ cat. 1

The addition of benzonitrile and acetonitrile to amido complex 1 led to a complex mixture of products. However, reaction with phenylacetonitrile in benzene- $d_{6}$ resulted in ammonia formation and clean conversion to keteniminate complex 9a in $79 \%$ yield

(29) Smid, J. In Spectrophotometric Studies of Ion-Pair Equilibria; Szwarc, M., Ed.; Wiley-Interscience: New York, 1972; Vol. 1, pp 85-151. (30) Kaplan, A. W.; Bergman, R. G. Organometallics 1998, 17, 5072.

4724 J. AM. CHEM. SOC. - VOL. 124, NO. 17, 2002 


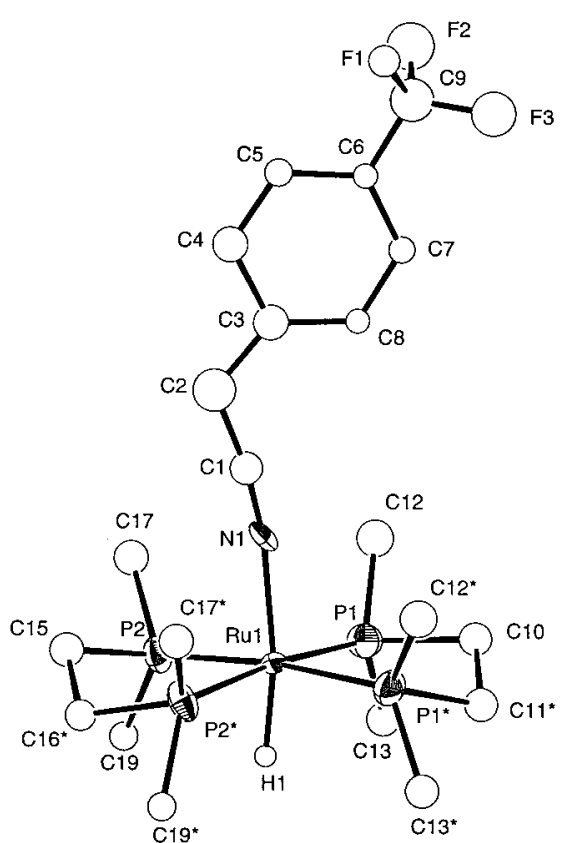

Figure 2. ORTEP diagram of $\mathbf{9 b}$. The disorder in the structure is not shown.

after $8 \mathrm{~h}$ at $25^{\circ} \mathrm{C}$ (Scheme 2). Similarly, addition of $4-(\alpha, \alpha, \alpha-$ trifluoromethyl)phenylacetonitrile to amido complex 1 resulted in the formation of a purple solution of keteniminate complex 9b in $74 \%$ yield after $1 \mathrm{~h}$ at $25^{\circ} \mathrm{C}$ (Scheme 2). X-ray quality crystals were grown by slowly cooling a concentrated toluene solution of $9 \mathbf{b}$ to $-30{ }^{\circ} \mathrm{C}$. An X-ray diffraction study confirmed the connectivity shown in Scheme 2; the ORTEP diagram is shown in Figure 2. Crystal and data collection parameters are given in Table 1, and selected intramolecular distances and bond angles are given in Table 2. The molecule lies on a crystallographic mirror plane within the unit cell, and thus only half of the molecule is unique. This requires disorder in the trifluoromethyl group and the two DMPE ligands, limiting the accuracy of the structure determination. However, the analysis clearly shows the connectivity of $\mathbf{9 b}$, and the bond distances are consistent with other known keteniminate complexes. ${ }^{31,32}$

Addition of cyclobutanone to amido complex $\mathbf{1}$ also resulted in ammonia displacement and the generation of a carbon-bound enolate complex (10) in 59\% yield after $8 \mathrm{~h}$ at $25{ }^{\circ} \mathrm{C}$ (Scheme 2). The ${ }^{1} \mathrm{H}$ NMR spectrum of $\mathbf{1 0}$ reveals five inequivalent broad proton resonances integrating to one proton each. The ${ }^{13} \mathrm{C}\left\{{ }^{1} \mathrm{H}\right\}$ NMR spectrum contains signals due to two methylene carbons at $\delta 41.8$ and 23.5, a quaternary carbon at $\delta 212.7$, and a quintuplet corresponding to a methine resonance at $\delta 40.47\left(J_{\mathrm{C}-\mathrm{P}}\right.$ $=18.5 \mathrm{~Hz}$ ). The IR spectrum reveals a strong band at 1636 $\mathrm{cm}^{-1}$, indicative of a carbonyl moiety, along with a band at $1832 \mathrm{~cm}^{-1}$ corresponding to the $\mathrm{Ru}-\mathrm{H}$ stretch. The carbonyl frequency is substantially red-shifted as compared to that in cyclobutanone, presumably due to interaction of the $\mathrm{C}=\mathrm{O} \pi$ system with the $\alpha$-metal-carbon bond. ${ }^{33-35}$ These data imply

(31) Bruce, M. I.; Wallis, R. C.; Skelton, B. W.; White, A. H. J. Chem. Soc., Dalton Trans. 1981, 2205.

(32) Tellers, D. M.; Ritter, J. C. M.; Bergman, R. G. Inorg. Chem. 1999, 38 , 4810.

(33) Albéniz, A. C.; Catalina, N. M.; Espinet, P.; Redón, R. Organometallics 1999, 18,5571 .

(34) Hartwig, J. F.; Andersen, R. A.; Bergman, R. G. J. Am. Chem. Soc. 1990 112,5670

(35) Hartwig, J. F.; Bergman, R. G.; Andersen, R. A. Organometallics 1991, $10,3326-3344$

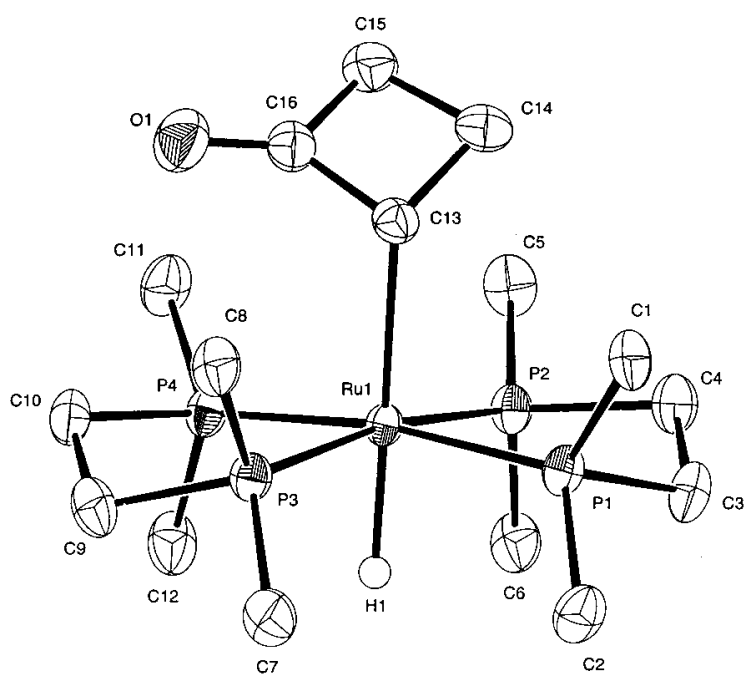

Figure 3. ORTEP diagram of 10, first enantiomer in the unit cell.

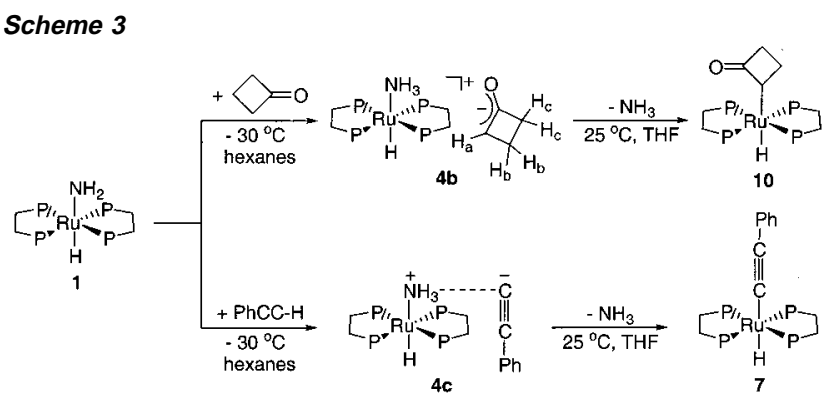

that the enolate moiety is bound through the $\beta$-carbon of the cyclobutanone functionality.

The proposed connectivity was confirmed by an X-ray diffraction study on a single crystal grown by slowly cooling a concentrated diethyl ether solution to $-30^{\circ} \mathrm{C}$. Two independent molecules exist in the asymmetric unit; an ORTEP diagram of one of the enantiomers is shown in Figure 3. Crystal and data collection parameters are given in Table 1, and selected intramolecular distances and bond angles are given in Table 2 . The $\mathrm{C}-\mathrm{O}$ bond distance of 1.218(4) $\AA$ is longer than that of a typical carbon-oxygen double bond, and the $\mathrm{C} 1-\mathrm{C} 2$ bond length of 1.451(5) $\AA$ is shorter than that of the other carboncarbon bonds in the cyclobutanone moiety, indicating significant electronic delocalization within the enolate system.

Mechanism of Ammonia Displacement: Formation of a Metastable Ammonia-Bound Ion Pair Intermediate. Mechanistic insight was gained by monitoring the reactions of amido complex 1 with cyclobutanone and phenylacetylene. An intermediate that we believe is the (possibly hydrogen-bonded; see next section) ammonia-bound complex $\mathbf{4 b}$ (Scheme 3) is observed upon monitoring the reaction between amido complex 1 and cyclobutanone by ${ }^{1} \mathrm{H}$ and ${ }^{13} \mathrm{C}\left\{{ }^{1} \mathrm{H}\right\}$ NMR spectroscopy. The ${ }^{1} \mathrm{H}$ NMR spectrum taken after $10 \mathrm{~min}$ at $25{ }^{\circ} \mathrm{C}$ in THF- $d_{8}$ reveals a singlet corresponding to the enolate proton $\mathrm{H}_{\mathrm{a}}$ at $\delta$ 3.36 and singlet resonances due to protons $\mathrm{H}_{\mathrm{b}}$ and $\mathrm{H}_{\mathrm{c}}$ at $\delta 1.71$ and 2.13 , respectively. The resonances corresponding to the bound $\mathrm{NH}_{3}$ hydrogens are found at $\delta 2.38$. The $\mathrm{NH}_{3}$ resonance is observed downfield relative to the $\mathrm{NH}_{3}$ protons of the fluorenide ion pair $\mathbf{4 a}$, indicating a decrease in electron density around these protons perhaps due to hydrogen bonding to the enolate anion. The ${ }^{13} \mathrm{C}\left\{{ }^{1} \mathrm{H}\right\}$ NMR spectrum revealed the 
Table 3. Selected IR Data ${ }^{a}$ (in $\mathrm{cm}^{-1}$ ) for Ion Pairs $\mathbf{4 a}, \mathbf{4 b}, \mathbf{4 c}, \mathbf{4 d}$, $\mathbf{4 e}, \mathbf{4 f}$, and $\mathbf{4 g}$

\begin{tabular}{|c|c|c|c|c|c|c|c|}
\hline & $4 a$ & $4 \mathrm{~b}$ & $4 c$ & $4 d$ & $4 e$ & $4 f$ & $4 \mathrm{~g}$ \\
\hline $\mathrm{NH}_{3}:{ }^{b}$ & $\begin{array}{l}3331 \\
3272\end{array}$ & $\begin{array}{l}3353 \\
3296\end{array}$ & $\begin{array}{l}3361 \\
3256\end{array}$ & $\begin{array}{l}3351 \\
3312 \\
3223\end{array}$ & $\begin{array}{l}3357 \\
3295 \\
3282\end{array}$ & not observed & $\begin{array}{l}3235 \\
3182\end{array}$ \\
\hline $\begin{array}{l}\mathrm{Ru}-\mathrm{H} \\
\text { other }\end{array}$ & 1916 & $\begin{array}{l}1872 \\
\text { C-O: } 1597\end{array}$ & $\begin{array}{l}1920 \\
\mathrm{C} \equiv \mathrm{C}: 1994\end{array}$ & 1901 & 1878 & $\begin{array}{c}1869 \\
\text { O-H: } 2653,2518\end{array}$ & 1902 \\
\hline
\end{tabular}

${ }^{a}$ All data taken in Nujol mulls. The $\mathrm{O}-\mathrm{H}$ stretch for $\mathrm{MeOH}$ in Nujol appears at $3370 \mathrm{~cm}^{-1}$ (br). ${ }^{b}$ Symmetric and asymmetric.

Table 4. Selected ${ }^{1} \mathrm{H}$ NMR (in ppm, THF- $d_{8}$ Solvent) Data for Ion Pairs 4a, 4b, 4c, 4d, 4e, 4f, and 4g

\begin{tabular}{lccccccc}
\hline & $4 a$ & $4 b$ & $4 c$ & $4 d$ & $4 e$ & $4 f$ & $4 g$ \\
\hline $\mathrm{NH}_{3}$ & -0.6 & 2.38 & 2.50 & $2.53^{b}$ & $2.55^{c}$ & $3.31^{b}$ & $2.92^{d}$ \\
$\mathrm{Ru}-\mathrm{H}$ & -20.34 & $-19.4^{a}$ & $-19.19^{a}$ & $-19.48^{b}$ & $-19.45^{c}$ & $-19(\mathrm{br})$ & $-19.34^{d}$
\end{tabular}

${ }^{a} 222 \mathrm{~K} .{ }^{b} 193 \mathrm{~K} .{ }^{c} 203 \mathrm{~K} .{ }^{d} 213 \mathrm{~K}$.

\section{Scheme 4}

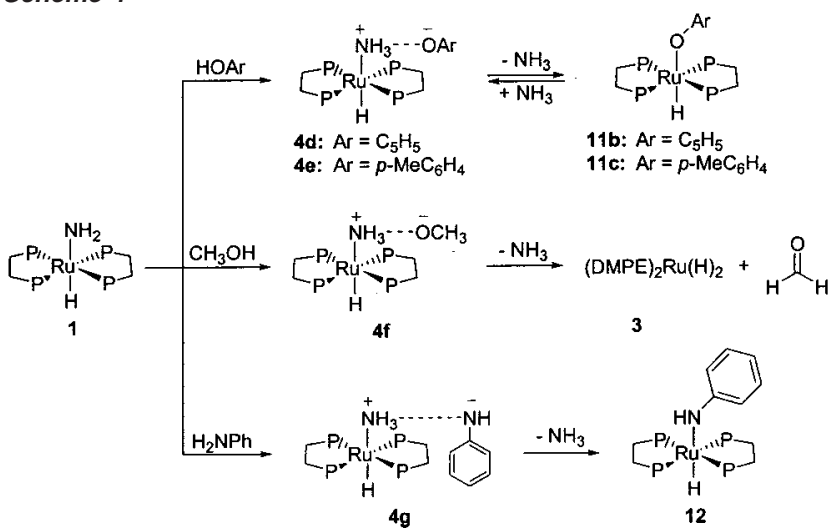

presence of two methylene carbons and one methine carbon. The symmetric and asymmetric stretching vibrations for the $\mathrm{N}-\mathrm{H}$ bond were observed at 3353 and $3296 \mathrm{~cm}^{-1}$ in the IR spectrum, along with a $\mathrm{Ru}-\mathrm{H}$ stretch at $1872 \mathrm{~cm}^{-1}$ and a $\mathrm{C}-\mathrm{O}$ stretching vibration at $1597 \mathrm{~cm}^{-1}$. Addition of a hexanes solution of cyclobutanone to a hexanes solution of amido complex 1 resulted in the precipitation of complex $\mathbf{4 b}$. This white solid can be kept indefinitely at room temperature. Upon redissolution of the solid in THF or benzene, the ion pair $\mathbf{4 b}$ can be observed, but it disappears concurrently with formation of the carbonbound enolate complex $\mathbf{1 0}$ and ammonia.

Similarly, addition of phenylacetylene to 1 in THF- $d_{8}$ resulted in immediate formation of an ammonia-bound ruthenium cation/ phenylacetylide anion pair $\mathbf{4 c}$ (Scheme 3, see Tables 3 and 4 for relevant IR and ${ }^{1} \mathrm{H}$ NMR data). Addition of a hexanes solution of phenylacetylene to a hexanes solution of amido complex 1 resulted in the precipitation of complex $\mathbf{4 c}$. Like $\mathbf{4 b}$, this tan solid can be kept indefinitely at low temperatures. However, upon redissolution in THF- $d_{8}$ or $\mathrm{C}_{6} \mathrm{D}_{6}$, the ion pair $\mathbf{4 c}$ is observed by NMR spectroscopy to disappear concurrently with formation of the phenylacetylide complex.

Reaction of 1 with Alcohols and Amines: Evidence for Hydrogen Bonding in the Ion Pair. Addition of phenol, $p$-cresol, methanol, and aniline to amido complex $\mathbf{1}$ resulted in the formation of ion pairs $\mathbf{4 d}, \mathbf{4 e}, \mathbf{4 f}$, and $\mathbf{4 g}$, respectively (Scheme 4). The relevant IR and NMR data are presented in Tables 3 and 4. In all cases, white powders of the ion pairs are isolated cleanly by mixing a hexanes solution of amido complex

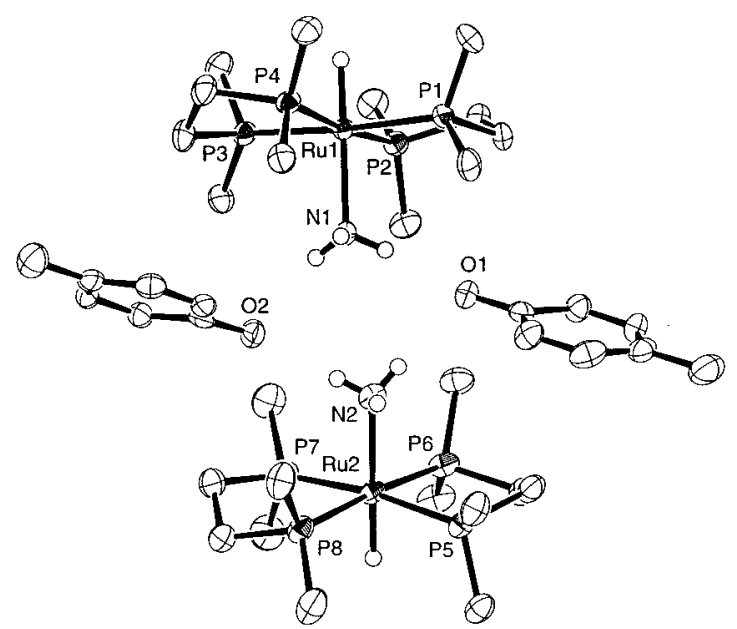

Figure 4. ORTEP diagram of $4 \mathbf{e}$. The ruthenium hydrides and the nitrogen hydrogens were located. The disordered solvent molecule is not shown.

1 with a hexanes solution of the substrate followed by removal of the volatile materials under reduced pressure.

$\mathrm{X}$-ray quality crystals of $\mathbf{4} \mathbf{e}$ were grown by slowly cooling a concentrated THF solution of cresolate ion pair 4e layered with pentane to $-30{ }^{\circ} \mathrm{C}$ for 1 month, and an X-ray diffraction study was carried out. An ORTEP diagram is shown in Figure 4. Crystal and data collection parameters are given in Table 1, and selected intramolecular distances and bond angles are given in Table 2. The hydride and the $\mathrm{N}-\mathrm{H}$ protons were located in the difference Fourier map. A disordered solvent molecule cocrystallized within the asymmetric unit cell. The ion pair $4 \mathbf{e}$ exists as a hydrogen-bonded dimer in the solid state with two ruthenium ammonia cations bridged by two cresolate anions. The average distance between nitrogen and oxygen is $2.932 \AA$, indicative of hydrogen bonding between these two atoms. Two of the ammonia hydrogens participate in the hydrogen bonding, while the other is orthogonal to the hydrogen bonding plane. ${ }^{36}$ The ruthenium - nitrogen bond length of $2.251 \AA$ is very similar to that found in the crystal structure of the fluorenide ion pair 4a.

In the aryl alcohol cases, ammonia displacement was observed. However, in sharp contrast to the reactions with carbon acids, an equilibrium was established over $1 \mathrm{~h}$ between the ion pairs $\mathbf{4 d}$ and $\mathbf{4 e}$ and their corresponding rutheniumphenolate or -cresolate complexes $\mathbf{1 1 b}$ and 11c and ammonia (Scheme 4)..$^{30,37}$ Cooling the reaction mixture to $-50{ }^{\circ} \mathrm{C}$ results in a change in the ratio of ruthenium complexes favoring the ion pairs $4 \mathbf{d}$ or $4 \mathbf{e}$. Warming the reaction mixture to $25^{\circ} \mathrm{C}$ results in the reestablishment of the original distribution. Addition of excess ammonia to the reaction mixtures at $25{ }^{\circ} \mathrm{C}$ shifts the equilibrium in favor the ion pairs $\mathbf{4 d}$ or $\mathbf{4 e}$. Similarly, addition of ammonia to pure ruthenium-phenolate complex $\mathbf{1 1 b}$ or ruthenium-cresolate complex 11c results in the formation of ion pair $\mathbf{4 d}$. These observations are all consistent with the presence of a rapidly equilibrating mixture of $\mathbf{1}, \mathbf{4 d}$, and $\mathbf{1 1 b}$ or $\mathbf{1}, \mathbf{4 e}$, and 11c.

In the case of methanol, the expected ruthenium-methoxide complex was not observed after ion pair formation. Instead,

(36) For an example of a platinum-bound ammonia complex which is hydrogen bonded to an aryloxide anion, see: Sigel, R. K. O.; Freisinger, E.; Metzger, S.; Lippert, B. J. Am. Chem. Soc. 1998, 120, 12000

(37) Burn, M. J.; Fickes, M. G.; Hollander, F. J.; Bergman, R. G. Organometallics 1995, 14, 137. 
complex $4 \mathbf{f}$ disappears concurrent with formation of dihydride 3, formaldehyde, and ammonia over $1.5 \mathrm{~d}$ at $25^{\circ} \mathrm{C}$. However, in analogy to the reactions observed between $\mathbf{1}$ and the aforementioned carbon acids, ion pair $\mathbf{4 g}$ forms the known anilido complex 12 and ammonia after $1 \mathrm{~d}$ at $25{ }^{\circ} \mathrm{C}$ in THF or benzene. ${ }^{37}$ Confirming the exoergicity of this reaction, addition of ammonia to a THF- $d_{8}$ solution of ruthenium-anilido complex $\mathbf{1 2}$ did not result in the formation of anilido ion pair $\mathbf{4 g}$ or amido complex 1.

H/D Exchange Reactions with Very Weak Acids. Amido complex 1 also reacts with exceedingly weak acids. One of the most striking reactions of $\mathbf{1}$ occurs upon its dissolution in toluene- $d_{8}$. Monitoring this reaction by ${ }^{1} \mathrm{H}$ and ${ }^{2} \mathrm{H}\left\{{ }^{1} \mathrm{H}\right\}$ NMR spectroscopy revealed complete deuterium incorporation into the N-bound positions of the amido complex $\mathbf{1}$ followed by deuterium incorporation into the methylene and methyl protons of the DMPE ligand itself, concurrent with hydrogen incorporation into the benzyl position of toluene (eq 6).

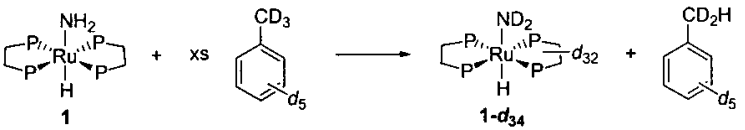

A similar, albeit slower, exchange is observed with hydroxo complex 2. Hydrogen incorporation into the aryl ring of toluene is not observed, and deuterium is not incorporated into the ruthenium hydride position. Surprisingly, in contrast to the behavior of 1 with the stronger acids discussed above, no displacement of ammonia to form the benzyl complex $\mathbf{1 3}$ is observed, even at elevated temperatures (eq 7). In control experiments, treatment of a solution of trans-(DMPE) $)_{2} \mathrm{Ru}(\mathrm{H})$ (Cl) with benzylmagnesium chloride generated the benzyl complex 13 in $35 \%$ yield after $3 \mathrm{~h}$ at $25^{\circ} \mathrm{C}$. Dissolution of $\mathbf{1 3}$ into liquid ammonia did not result in the conversion of the benzyl complex $\mathbf{1 3}$ to the amido complex $\mathbf{1}$.

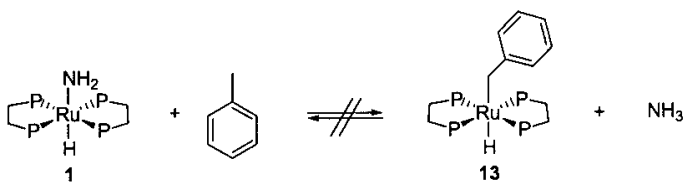

H/D Exchange Reactions Catalyzed by Amidoruthenium Complex 1. Consistent with the observation that amido complex 1 undergoes H/D exchange with toluene, complex 1 can also be used to catalyze deuterium exchange between toluene- $d_{8}$ and carbon acids of similar or stronger acidities but widely varying bond dissociation energies (Table 5 and eq 8).

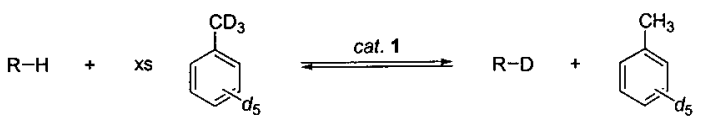

Compounds that do undergo H/D exchange include triphenylmethane, cycloheptatriene, ammonia, dihydrogen, and propene; those that do not (even at elevated temperatures) include benzene, THF, ethylene, and $N$ - $N$-dimethyl- $p$-toluidine. Exposure of $\mathbf{1}$ for extended periods to an atmosphere of dihydrogen or ethylene results in the loss of ammonia and formation of either the dihydride complex $\mathbf{3}$ or the ethylene complex (DMPE) $)_{2} \mathrm{Ru}\left(\mathrm{C}_{2} \mathrm{H}_{4}\right)$, respectively. No detectable amounts of radical coupling products such as bibenzyl (from toluene),
Table 5. $p K_{a}$ 's and BDEs of Compounds Reactive toward Amido Complex 1

\begin{tabular}{|c|c|c|}
\hline compound & $\mathrm{pK} K_{\mathrm{a}}$ & $\mathrm{BDE}\left(\mathrm{kcal} \mathrm{mol}^{-1}\right)$ \\
\hline phenol & $18.0(\mathrm{DMSO})^{a}$ & $89.95^{b}$ \\
\hline $\begin{array}{l}\text { 4-( } \alpha, \alpha, \alpha \text {-trifluoromethy)- } \\
\text { phenylacetonitrile }\end{array}$ & $18^{c}$ & $\sim 84$ \\
\hline p-cresol & 18.9 (DMSO) & $88.7^{d, e}$ \\
\hline phenylacetonitrile & $22.3^{c}$ & $84.7^{d}$ \\
\hline fluorene & $22.9(\mathrm{THF})^{f}$ & $80^{g}$ \\
\hline cyclobutanone & $25.1(\text { DMSO })^{h}$ & \\
\hline phenylacetylene & $28.7(\mathrm{DMSO})^{h}$ & $>125^{a, j}$ \\
\hline methanol & $29.0\left(\mathrm{DMSO}^{j}\right.$ & $102(\mathrm{O}-\mathrm{H})^{j}$ \\
\hline water & $31.2\left(\mathrm{DMSO}^{c}\right.$ & $118.1^{k}$ \\
\hline triphenylmethane & $31.5(\mathrm{THF})^{f}$ & $84^{g}$ \\
\hline dihydrogen & $35^{j}$ & $104^{j}$ \\
\hline cycloheptatriene & $38.8^{j}$ & $73^{i}$ \\
\hline ammonia & $41^{h}$ & $107.4^{i}$ \\
\hline toluene & $41^{j}$ & $88.0^{l}$ \\
\hline propene & $43^{j}$ & $86.3^{l}$ \\
\hline benzene & $43^{j}$ & $110.9^{l}$ \\
\hline
\end{tabular}

${ }^{a}$ Bordwell, F. G.; McCallum, R. J.; Olmstead, W. N. J. Org. Chem. 1984, 49, 1424. ${ }^{b}$ Bordwell, F. G.; Cheng, J.-P. J. Am. Chem. Soc. 1991, 113, 1736. ' ${ }^{c}$ Bordwell, F. G.; Bauxch, M. J. J. Am. Chem. Soc. 1986, 108 , 1979. ${ }^{d}$ Reference 65b. ${ }^{e}$ Zhang, X.-M.; Bordwell, F. G. J. Am. Chem. Soc. 1994, 116, 968. ${ }^{f}$ Streitwieser, A.; Wang, D. Z.; Stratakis, M.; Facchettis, A.; Gareyev, R.; Abbotto, A.; Krom, J. A.; Kilway, K. V. Can. J. Chem. 1998, 76, 765. ${ }^{g}$ Bordwell, F. G.; Cheng, J.-P.; Ji, G.-Z.; Satish, A. V.; Zhang, X. J. Am. Chem. Soc. 1991, 113, 9790. ${ }^{h}$ Reference 54. ${ }^{i}$ Reference 52. ${ }^{j}$ Reference 55. ${ }^{k}$ Berkowitz, J.; Ellison, G. B.; Gutman, D. J. Phys. Chem. 1994, 98, 2744. ${ }^{l}$ Ellison, G. B.; Davico, G. E.; Bierbaum, V. M.; Depuy, C. H. Int. J. Mass Spectrom. Ion Processes 1996, 156, 109.

bicycloheptatrienyl (from cycloheptatriene), 1,5-hexadiene (from propene), hexaphenylethane (from triphenylmethane), or bifluorenyl (from fluorene) are observed in any of these reactions. 38,39

In analogy to the toluene reaction and in contrast to the behavior observed with stronger acids, no displacement of ammonia is observed in any of the exchange reactions between $\mathbf{1}$ and very weak acids listed above. This extends to $\mathrm{NH}_{2}$ as a potential entering group; despite rapid H/D exchange between 1 and $\mathrm{ND}_{3}$, addition of ${ }^{15} \mathrm{NH}_{3}$ to the amido complex does not result in incorporation of labeled nitrogen into the amido complex 1, even after extended reaction times (eq 9). Labeled nitrogen is observed in the presumably more thermodynamically stable cis isomer, which is formed irreversibly after 1 month at room temperature.

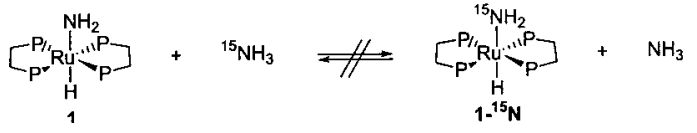

Equilibrium Measurements between the Amido and Hydroxo Complexes and Weak Acids of Similar Conjugate Base Strength. To obtain an estimate of the intrinsic basicity of $\mathbf{2}$, we examined the reaction of the hydroxo complex with several different carbon acids of moderate acidity in THF- $d_{8}$. In the case of fluorene, NMR analysis showed an equilibrium mixture of $\mathbf{2}$, fluorene, and the aquo-fluorenide complex $\mathbf{6 a}$ (eq 4). The $\lambda_{\max }$ of $368 \mathrm{~nm}$ compares well with other known contact ion pair (CIP) of fluorenide salts (vide infra). Assuming that the product is a CIP, the data at several different concentrations were analyzed according to the equilibrium expression in eq

(38) Vincow, G.; Dauben, H. J.; Hunter, F. R.; Volland, W. V. J. Am. Chem Soc. 1969, 91, 2823.

(39) Arends, I. W. C. E.; Mulder, P.; Clark, K. B.; Wayner, D. D. M. J. Phys. Chem. 1995, 99, 8182 . 


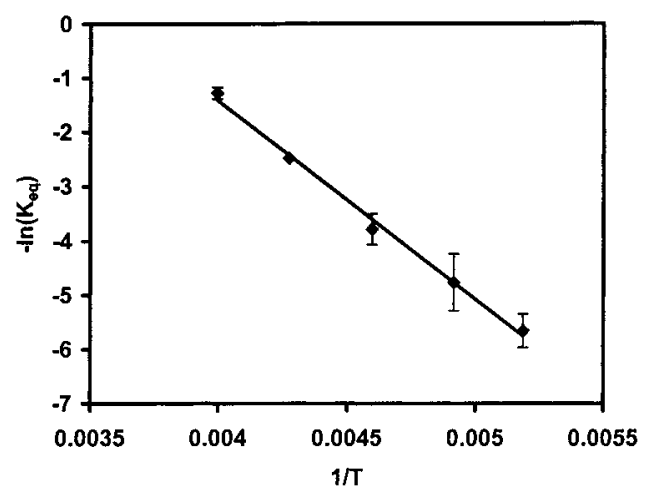

Figure 5. Van't Hoff plot of the equilibrium between amido 1, triphenylmethane, and the salt complex $\mathbf{4 h}$. This gives $\Delta H^{\circ}=-7.2 \pm 0.4 \mathrm{kcal} / \mathrm{mol}$ and $\Delta S^{\circ}=-26 \pm 2 \mathrm{eu}$.

10 , leading to a good fit and an equilibrium constant $\left(K_{\text {measured(6a) }}\right)$ of $6.4 \pm 0.5 \mathrm{M}^{-1}$ at $25^{\circ} \mathrm{C}$ for this process. The fact that an essentially invariant $K_{\text {measured }}$ value was obtained at several different concentrations supports the hypothesis that the products exist as a simple CIP in THF solution at $25^{\circ} \mathrm{C}$.

$K_{\text {measured(6a) }}=\frac{[6 \mathrm{a}]}{[2][\mathrm{F} 1-\mathrm{H}]}$

The more strongly basic amido complex 1 completely deprotonates fluorene. Addition of the weaker carbon acid triphenylmethane to amido complex 1 in THF- $d_{8}$ resulted in the formation of a pale-pink solution, suggesting that some triphenylmethide had been generated. However, it must have been a very small amount, since the ${ }^{1} \mathrm{H}$ NMR spectrum of the reaction mixture at $25{ }^{\circ} \mathrm{C}$ showed resonances due only to unreacted starting material. Upon cooling the reaction mixture to $253 \mathrm{~K}$, the color intensified, and three resonances in the aryl region of the ${ }^{1} \mathrm{H}$ NMR spectrum appeared in a 2:2:1 ratio. We have assigned these to the aryl resonances of $\mathrm{Ph}_{3} \mathrm{C}^{-}$. Further cooling resulted in a change in the intensities of the new resonances for $\mathrm{Ph}_{3} \mathrm{C}^{-}$relative to the resonances corresponding to $\mathrm{Ph}_{3} \mathrm{CH}$. These observations are consistent with the existence of a temperature-dependent equilibrium in which amido complex 1 deprotonates triphenylmethane to generate the $\mathrm{Ph}_{3} \mathrm{C}^{-} /$ammoniabound ruthenium ion pair $\mathbf{4 h}$ (eq 11). Integration at five different temperatures permitted evaluation of the equilibrium constants using the expression in eq 12. A van't Hoff plot allowed us to calculate $\Delta H^{\circ}=-7.2 \pm 0.4 \mathrm{kcal} \mathrm{mol}^{-1}$ and $\Delta S^{\circ}=-26 \pm 2$ eu (Figure 5). This leads to an extrapolated equilibrium constant of $4.0 \pm 0.4 \times 10^{-1} \mathrm{M}^{-1}$ at $25^{\circ} \mathrm{C}$.

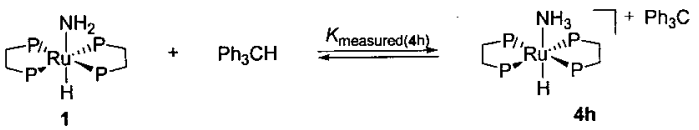

$K_{\text {measured(4h) }}=\frac{[4 \mathrm{~h}]}{[1]\left[\mathrm{Ph}_{3} \mathrm{CH}\right]}$

Theoretical Calculations. To gain a better understanding of the thermodynamics involved in proton transfer and ammonia displacement, several calculations were performed using the hybrid density functional theory (DFT) method with the B3LYP functional ${ }^{40,41}$ employing the Gaussian 99 series of programs. ${ }^{42-44}$

(40) Becke, A. D. J. Chem. Phys. 1993, 98, 5648.

(41) Lee, C.; Tang, W.; Parr, R. G. Phys. Rev. B 1988, 37, 785.
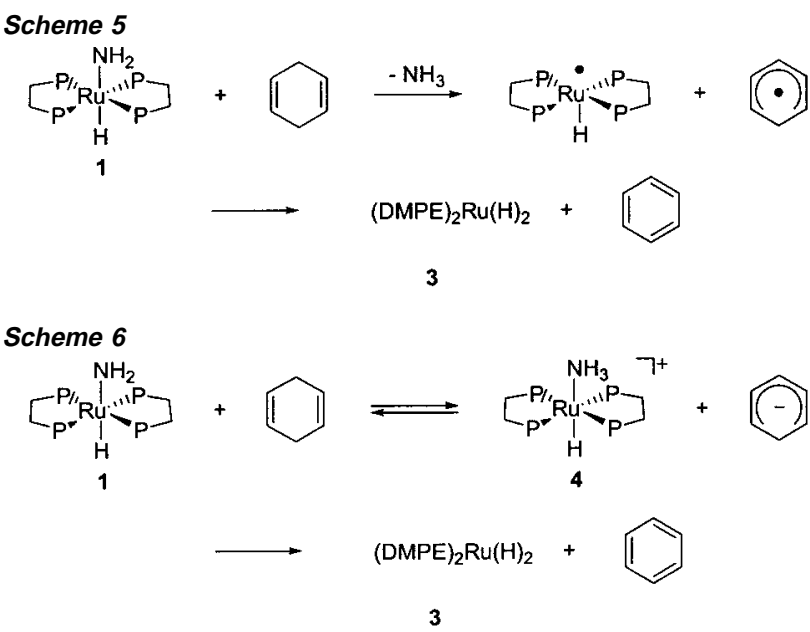

The details are provided in the Supporting Information, and the results are briefly covered at the end of the Discussion section below.

\section{Discussion}

Oxidation of 1,4-Dienes. The addition of 1,4-CHD to the amido complex 1 leads to the formation of benzene, ammonia, and the dihydride complex 3 (eq 1). This result may be relevant to the action of lipoxygenase, a non-heme iron-containing enzyme, which converts 1,4-fatty acid dienes to alkylhydroperoxides. ${ }^{7}$ The rate-determining step in this process has been proposed to be the homolytic cleavage of the weak $\mathrm{C}-\mathrm{H}$ bond in the organic substrate by an $\mathrm{Fe}-\mathrm{OH}$ intermediate. ${ }^{8-11,46,47}$ Stack's [Fe $\left.{ }^{\mathrm{III}}(\mathrm{PY} 5)(\mathrm{OMe})\right][\mathrm{OTf}]_{2}$ complex also dehydrogenates 1,4-CHD. ${ }^{4}$ This reaction was proposed to serve as a model for lipoxygenase, taking place by initial abstraction of a hydrogen atom. Mayer and co-workers have shown the feasibility of $\mathrm{M}-\mathrm{O}$ mediated radical reactions by demonstrating that $\left[(\text { phen })_{2} \mathrm{Mn}-\right.$ $\left.(\mu-\mathrm{O})_{2} \mathrm{Mn}(\text { phen })_{2}\right]\left[\mathrm{PF}_{6}\right]_{3}$ abstracts hydrogen atoms from weak $\mathrm{C}-\mathrm{H}$ bonds such as those found in DHA. ${ }^{5,6,48}$

The above transformations involve a thermodynamically accessible reduction of the metal species upon transfer of the hydrogen atom to the alkoxo ligand. ${ }^{4,5,11}$ The oxidation state change for our amido and hydroxo complexes (1 and 2 ) is presumably less favorable than the analogous reactions in these

(42) Frisch, M. J.; Trucks, G. W.; Schlegel, H. B.; Scuseria, G. E.; Robb, M. A.; Cheeseman, J. R.; Zakrzewski, V. G.; Montgomery, J. A., Jr.; Stratmann, R. E.; Burant, J. C.; Dapprich, S.; Millam, J. M.; Daniels, A. D.; Kudin, K. N.; Strain, M. C.; Farkas, O.; Tomasi, J.; Barone, V.; Mennucci, B Cossi, M.; Adamo, C.; Jaramillo, J.; Cammi, R.; Pomelli, C.; Ochterski, J.; Petersson, G. A.; Ayala, P. Y.; Morokuma, K.; Malick, D. K.; Rabuck, A. D.; Raghavachari, K.; Foresman, J. B.; Ortiz, J. V.; Cui, Q.;Baboul, A. G.; Clifford, S.; Cioslowski, J.; Stefanov, B. B.; Liu, G.; Liashenko, A.; Piskorz, P.; Komaromi, I.; Gomperts, R.; Martin, R. L.; Fox, D. J.; Keith, T.; Al-Laham, M. A.; Peng, C. Y.; Nanayakkara, A.; Challacombe, M.; Gill, P. M. W.; Johnson, B.; Chen, W.; Wong, M. W.; Andres, J. L.; Gonzalez, C.; Head-Gordon, M.; Replogle, E. S.; Pople, J. A. Gaussian 99, Development Version, revision B; Gaussian, Inc.: Pittsburgh, PA, 2000

(43) The geometries of all species were fully optimized. Vibration frequencies were also computed for all species to determine whether these species are minima, transition states, or higher order saddle points on the potential energy surface (PES) and for evaluating zero-point energies (ZPEs). The enthalpies of the species at $0 \mathrm{~K}(\mathrm{DH})$ were calculated as the sum of the absolute energies and the ZPE. The absolute energies, ZPEs, and Cartesian coordinates of all species are listed in the Supporting Information.

(44) See Supporting Information for experimental write-up.

(45) To simplify our calculations, the methyl groups on the DMPE ancillary ligands were replaced with hydrogen atoms (compound labels $\mathbf{1}^{\prime}, \mathbf{2}^{\prime}$, etc.)

(46) Jonsson, T.; Glickman, M. H.; Sun, S.; Klinman, J. P. J. Am. Chem. Soc. 1996, 118,10319

(47) Glickman, M. H.; Klinman, J. P. Biochemistry 1996, 35, 12882.

(48) Wang, K.; Mayer, J. M. J. Am. Chem. Soc. 1997, 119, 1470. 
first row systems. Still, the existence of a more difficult oxidation state change does not rigorously rule out a one-electron pathway in the oxidation of CHD or DHA by $\mathbf{1}$ or $\mathbf{2}$. One can envision a mechanism by which the nitrogen abstracts a hydrogen from the weak $\mathrm{C}-\mathrm{H}$ bond of $\mathrm{CHD}$ (bond dissociation energy $(\mathrm{BDE})=73 \mathrm{kcal} / \mathrm{mol})^{49}$ to generate ammonia, a cyclohexadienyl radical species, and a 17 electron $\mathrm{Ru}(\mathrm{I})$ complex (Scheme 5, which we will refer to as the "radical pathway"). The ruthenium radical can then abstract a second hydrogen atom from the cyclohexadienyl radical to generate benzene and the ruthenium dihydride complex 3.

An alternative mechanism postulates deprotonation of the weakly acidic $\mathrm{C}-\mathrm{H}$ bond of $\mathrm{CHD}$ to generate a transient ammonia-bound cationic ruthenium center and the cyclohexadienide anion (Scheme 6, the "ionic pathway"). This complex could lose ammonia and abstract a hydride directly from cyclohexadienide to afford the observed products or it could collapse to a cyclohexadienylruthenium complex, followed by $\beta$-hydride elimination to generate the dihydride complex 3 and benzene. To gain further evidence for either hypothesis, we extended this study to include the reactions between amido complex 1 and a variety of different organic substrates possessing a wide range of bond strengths and $\mathrm{p} K_{\mathrm{a}}$ 's.

Displacement of Ammonia Is Preceded by Formation of an Ammonia-Bound Cationic Ruthenium Complex. Reaction of Brønsted acids possessing $\mathrm{p} K_{\mathrm{a}}$ 's $<35$ with amido complex 1 led to exothermic deprotonation and, in many cases, displacement of ammonia. For example, exothermic deprotonation is observed in the reaction between $\mathbf{1}$ and fluorene, generating the fluorenide complex 4a (Scheme 1). The ionic nature of this complex is clearly demonstrated by its insolubility in aliphatic solvents and by its crystal structure (Figure 1). The salt $4 \mathbf{a}$ shows a nitrogen-aromatic ring distance of $3.00 \AA$, indicating a potentially stabilizing cation- $\pi$ interaction between the ammonium nitrogen and the fluorenide anion. ${ }^{50}$ No displacement of ammonia to generate the neutral ruthenium-fluorenide complex (5) was ever observed (Scheme 1).

Displacement reactions occurred with substrates possessing fewer steric constraints than fluorene and encompassing a wide range of $\mathrm{C}-\mathrm{H}$ bond strengths. For example, reaction of $\mathbf{1}$ with arylacetonitriles having $\mathrm{p} K_{\mathrm{a}}$ values similar to or lower than that of fluorene results in the formation of keteniminate complexes 9a or $\mathbf{9 b}$ and ammonia (Scheme 2). Similarly, addition of cyclobutanone to $\mathbf{1}$ leads to the formation of a carbon-bound (in preference to an oxygen-bound) enolate complex, a binding motif common for this ruthenium system (Scheme 2). ${ }^{30,33,34,51}$ Amido complex 1 also reacts with the terminal $\mathrm{C}-\mathrm{H}$ bond of phenylacetylene to generate the phenylacetylide complex 7 (Scheme 2), demonstrating that $\mathbf{1}$ reacts with very strong $\mathrm{C}-\mathrm{H}$ bonds $(\mathrm{BDE}>125 \mathrm{kcal} / \mathrm{mol})^{52,53}$ as long as they are relatively acidic $\left(\mathrm{p} K_{\mathrm{a}}=28.7\right) .{ }^{54}$ Similarly, amido complex 1 reacts with the more acidic $\mathrm{O}-\mathrm{H}$ bond $\left(\mathrm{p} K_{\mathrm{a}}=29.0,{ }^{54} \mathrm{BDE}=102 \mathrm{kcal} /\right.$ $\mathrm{mol})^{53}$ as opposed to the weaker $\mathrm{C}-\mathrm{H}$ bond $(\mathrm{BDE}=93 \mathrm{kcal} /$ $\mathrm{mol})^{53}$ of methanol (Scheme 4).

(49) Burkey, T. J.; Mafewski, M.; Griller, D. J. Am. Chem. Soc. 1986, 108, 2218

(50) Ma, J. C.; Dougherty, D. A. Chem. Rev. 1997, 97, 1303.

(51) Slough, G. A.; Bergman, R. G.; Heathcock, C. H. J. Am. Chem. Soc. 1989 111,938 .

(52) McMillen, D. F.; Golden, D. M. Annu. Rev. Phys. Chem. 1982, 33, 493.

(53) Lowry, T. H.; Richardson, K. S. Mechanism and Theory in Organic Chemistry, 3rd ed.; Harper and Row: New York, 1987.

(54) Bordwell, F. G. Acc. Chem. Res. 1988, 21, 456.

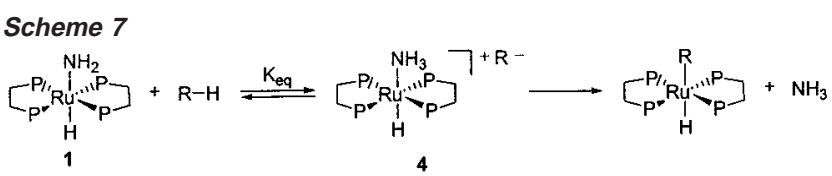

Scheme 8

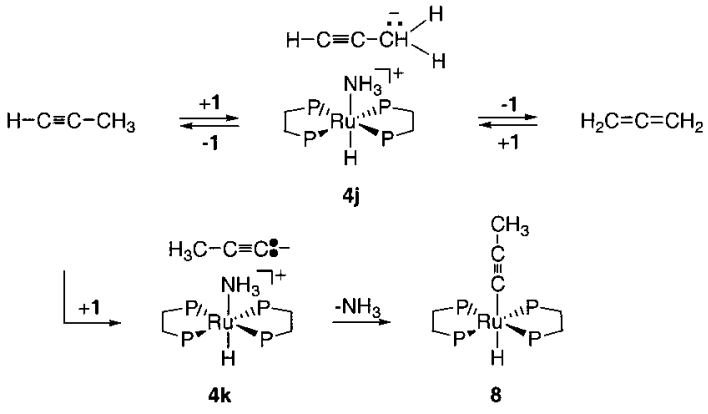

The observation of intermediates in the addition of cyclobutanone, phenylacetylene, aniline, methanol, and aryl alcohols to amido complex 1 provided evidence that displacement reactions proceed via ammonia-bound ruthenium ion pairs 4 (Scheme 7). The chemical shift of the resonance corresponding to the $\mathrm{N}-\mathrm{H}$ protons in ${ }^{1} \mathrm{H}$ NMR spectra of the intermediates appeared downfield of the $\mathrm{N}-\mathrm{H}$ resonance in the fluorenide ion pair 4a. This is indicative of a decrease in electron density around the $\mathrm{N}-\mathrm{H}$ protons and provides evidence that the above reactants form ion pairs that are held together (and presumably stabilized) by hydrogen bonding. All of the conjugate bases of the acids listed above are capable of forming strong hydrogen bonds to hydrogen bond donors. ${ }^{55}$

Addition of 1,2-propadiene to amido complex $\mathbf{1}$ results in the formation of the methylacetylide complex $\mathbf{8}$ exclusively, even though the amido complex catalyzes the interconversion of 1,2-propadiene and propyne (Scheme 8). Strong bases, including sodium amide in liquid ammonia, affect prototropic acetylene-allene rearrangements via carbanion intermediates. ${ }^{56,57}$ We believe the amido complex promotes the isomerization via a similar mechanism. Deprotonation of 1,2-propadiene or propyne generates the propynyl anion/ruthenium-ammonia complex $\mathbf{4 j}$. Reprotonation can occur at either end of the anion; repetition of this sequence ultimately generates a thermodynamically controlled mixture of $\mathrm{C}_{3}$ species. Apparently, the more exoergic reaction in this system involves loss of ammonia and generation of a methylacetylide complex $(\mathbf{8})$ via deprotonation of the terminal hydrogen of propyne which initially generates the ion pair $\mathbf{4 k}$. If 3-propynyl or allenylruthenium complexes are formed during this reaction, they must either be generated reversibly or rearrange to the methylacetylide complex $\mathbf{8}$.

Addition of methanol to amido complex 1 results in immediate formation of the methoxide ion pair $4 \mathbf{f}$ (Scheme 9). In contrast to our observations with other nucleophilic counterions, no covalent ruthenium methoxide complex 11a is observed after ammonia displacement. Instead, formaldehyde and dihydride complex $\mathbf{3}$ are generated. These are the expected products of $\beta$-hydride transfer in the ion pair, or $\beta$-hydride elimination from the neutral ruthenium-methoxide complex 11a (Scheme 9). This

(55) Chabinyc, M. L.; Brauman, J. I. J. Am. Chem. Soc. 2000, 122, 8739.

(56) Cram, D. J. Stereochemistry of Substitution of Carbon Acids and Organometallic Compounds; Academic Press: New York, 1965; Vol. 4.

(57) Landor, P. D. In Synthesis of Allenes; Landor, S. R., Ed.; Academic Press: London, 1982; Vol. 1, pp 44-61. 


\section{Scheme 9}
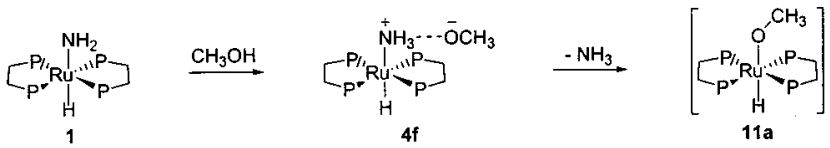

$(\mathrm{DMPE})_{2} \mathrm{Ru}(\mathrm{H})_{2}+\mathrm{H}_{\mathrm{H}}$

overall reaction is a common pathway of decomposition for many late-metal alkoxide complexes., ${ }^{1,58-60}$

Reaction between Amido Complex 1 and Aryl Alcohols: Reversible Displacement of Ammonia. Addition of phenol to amido complex $\mathbf{1}$ results in the formation of an equilibrium mixture of the phenolate ion pair $\mathbf{4 d}$ and the rutheniumphenolate complex 11b and ammonia (Scheme 4). The ion pair exists as a hydrogen bonded dimer in the solid state, similar to our previously reported ruthenium hydroxo/aquo complex [trans-(DMPE) $\left.)_{2} \mathrm{Ru}(\mathrm{H})(\mathrm{OH})\right]_{2}\left[\mathrm{H}_{2} \mathrm{O}\right]_{2} \cdot{ }^{61}$ Most aryloxide hydrogen bonded complexes are monomeric in the solid state. ${ }^{15,16,59,62-64}$ However, Canty's palladium-aquo/pentafluoro phenolate complex was observed to crystallize as a dimer. ${ }^{62}$ Ion pair $\mathbf{4 d}$ may form dimers or more complicated aggregates in solution; we have not yet been able to obtain definitive evidence for its solution structure by NMR.

The equilibrium established between the aryloxide ion pairs $\mathbf{4 d}$ and $\mathbf{4 e}$ and their corresponding ruthenium-aryloxide complexes 11b and 11c and ammonia in THF- $d_{8}$ is intriguing (Scheme 4). Apparently, the ion pairs and neutral complexes have comparable free energies in THF at $25^{\circ} \mathrm{C}$. Although equilibrium constant measurements in other cases were successful, attempts to quantify the equilibrium constant between $\mathbf{1 1}$ and $\mathbf{4}$ led to inconclusive results. Apparent $K_{\text {eq }}$ 's measured in dilute solutions were larger than those obtained in more concentrated solutions, indicating the possible formation of larger aggregates in the more concentrated solutions.

The reason for the low barrier to ammonia displacement in the aryloxide ion pairs $\mathbf{4 d}$ and $\mathbf{4} \mathbf{e}$ relative to those in the anilido (4g) and methoxide (4f) ion pairs is unclear. Similar systems, such as phenylacetylide ion pair $\mathbf{4 c}$, methoxide ion pair $\mathbf{4 f}$, or anilido ion pair $\mathbf{4 g}$ irreversibly lose ammonia over the course of at least 1 day, and the enolate ion pair $\mathbf{4 b}$ loses ammonia over the course of $8 \mathrm{~h}$. However, in the aryloxide examples, loss of ammonia is fairly rapid and reversible. This indicates a low-energy pathway for ammonia displacement, potentially a function of the relative stability of the anion. Qualitatively, as long as they are not too sterically hindered (e.g., as in fluorenide ion pair $\mathbf{4 a}$ ), the more stable anions displace ammonia faster than do the less stable anions. Possible reasons for this are discussed below.

H/D Exchange Reactions: Evidence for an Extremely Basic Amido Ligand. The deprotonation and displacement

(58) Blum, O.; Milstein, D. J. Organomet. Chem. 2000, 594, 479.

(59) Kuznetsov, V. F.; Yap, G. P. A.; Bensimon, C.; Alper, H. Inorg. Chim. Acta 1998, 280, 172.

(60) Newman, L. J.; Bergman, R. G. J. Am. Chem. Soc. 1985, 107, 5314

(61) Burn, M. J.; Fickes, M. G.; Hartwig, J. F.; Hollander, F. J.; Bergman, R. G. J. Am. Chem. Soc. 1993, 115, 5875.

(62) Canty, A. J.; Jin, H.; Skelton, B. W.; White, A. H. J. Organomet. Chem. 1995, 503, C16.

(63) Haarman, H. F.; Kaagman, J.-W. F.; Smeets, W. J. J.; Spek, A. L.; Vrieze, K. Inorg. Chim. Acta 1998, 270, 34

(64) Kim, Y.-J.; Choi, J.-C.; Osakada, K. J. Organomet. Chem. 1996, 491, 97.

\section{Scheme 10}

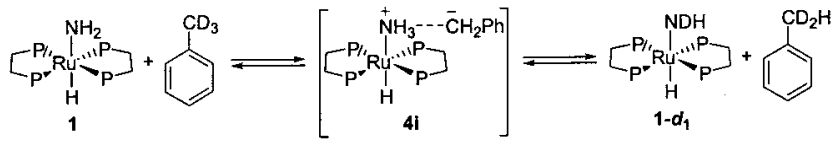

reactions discussed above clearly demonstrate the basic nature of the metal-bound $\mathrm{NH}_{2}$ ligand in amido complex 1 . The reaction of $\mathbf{1}$ with exceptionally weak acids, such as ammonia, toluene, and the ruthenium-bound DMPE ligands, is even more dramatic. In these cases, the use of deuterium-labeled reaction partners reveals that the ruthenium amide is capable of effecting $\mathrm{H} / \mathrm{D}$ exchange at a reasonable rate at room temperature. In contrast to the behavior of $\mathbf{1}$ with stronger acids, no displacement of ammonia is observed in these cases.

As with the displacement reactions discussed above, the $\mathrm{p} K_{\mathrm{a}}$, and not the bond dissociation energy, of the substrate appears to be the physical property that controls the rate of $H / D$ exchange. For example, no H/D exchange was observed with the benzyl methyl hydrogens of $N$ - $N$-dimethyl- $p$-toluidine, even though they have bond dissociation energies similar to that of toluene. We believe this lack of reactivity is due to the lower acidity of the benzyl protons of $N, N$-dimethyl- $p$-toluidine. ${ }^{65}$ Similarly, amido complex 1 undergoes H/D exchange with ammonia, despite the exceptionally high $\mathrm{NH}_{3}$ bond dissociation energy $(107.4 \mathrm{kcal} / \mathrm{mol})$. Additional evidence against a radical pathway was provided by the treatment of amido complex $\mathbf{1}$ with a variety of poorly acidic substrates that possess particularly weak $\mathrm{C}-\mathrm{H}$ bonds, such as cycloheptatriene (BDE $=73 \mathrm{kcal} /$ mol). Although these complexes were observed to undergo H/D exchange, no products from radical dimerization, such as the formation of bicycloheptatrienyl from cycloheptatriene, were ever observed. ${ }^{38,39}$ These results provide further support for a two-electron, rather than a one-electron, pathway in these reactions, and by extension in the oxidation of the weakly acidic hydrocarbons cyclohexadiene and 9,10-dihydroanthracene.

The most obvious mechanism for H/D exchange between amido complex $\mathbf{1}$ and the benzyl protons of toluene is the reversible formation of ion pair $\mathbf{4 i}$ (Scheme 10). However, as noted above, displacement of ammonia by a transiently generated benzyl anion to generate benzylruthenium complex $\mathbf{1 3}$ is not observed (eq 7). Analogously, ${ }^{15} \mathrm{~N}$ from free ${ }^{15} \mathrm{NH}_{3}$ is not incorporated into amido complex 1 (eq 9). Because rapid H/D exchange between the amido protons $\mathbf{1}$ and the benzyl protons of toluene occurs at $25{ }^{\circ} \mathrm{C}$, either ion pair $4 \mathbf{i}$ must be energetically accessible at that temperature or the proton transfer must proceed via a concerted transition state similar to that shown in Figure 6.

Interestingly, acids which lead to strongly basic anions result in ammonia displacement more slowly than those which lead to weaker bases (vide supra). We propose to address this surprising result using the picture of the overall displacement mechanism illustrated in Scheme 11. After the initial reversible proton transfer step, it seems likely that loss of ammonia is preceded by the (presumably also reversible) rupture of the $\mathrm{RuNH}_{3}{ }^{+} \cdot \mathrm{A}^{-}$hydrogen bond in ion pair 4 , leading to solventseparated ion pair 14. Rapid collapse of the resulting ion pair 15 (a dissociative mechanism for this process is illustrated, but

(65) The BDEs of $\mathrm{C}-\mathrm{H}$ bonds in substituted toluenes are not substantially affected by para-substituents, see: (a) Zhang, X.-M.; Bruno, J. W.; Enyinnaya, E. J. Org. Chem. 1998, 63, 4671. (b) Wayner, D. D. M.; Sim, B. A. J. Org. Chem. 1991, 56, 4853. 


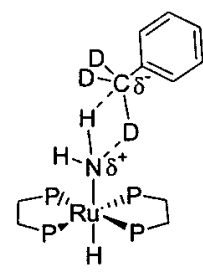

Figure 6. Proposed transition state for H/D exchange between amido complex 1 and toluene.

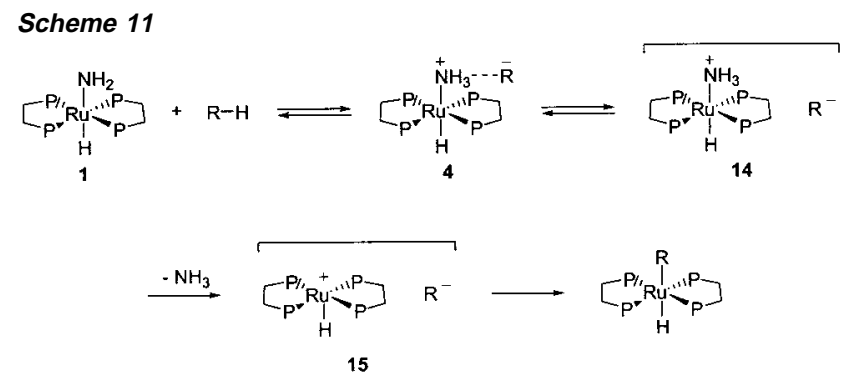

the displacement could be associative) would then lead to the covalent product.

In the case of acids such as phenol, cyclobutanone, etc., the initial reaction with $\mathbf{1}$ is either energetically downhill or close to thermoneutral, leading to substantial concentrations of the initial ion pair that results from proton transfer. The free energy barrier that must be crossed to give the final displacement product is then only that associated with further reaction of the ion pair. In the case of very weak acids, the positive $\Delta G^{\circ}$ associated with proton transfer must be added to that of $\Delta G^{\ddagger}$ for displacement reaction itself to give the overall free energy of the displacement reaction from starting material to product. It seems likely that this combined $\Delta G^{\ddagger}$ is too high to lead to displacement, and so only exchange is observed. There may also be a higher energetic cost for the second (ion-pair dissociating) step in Scheme 11 if the anion is extremely basic. Finally, in the case of some very weak acids, proton transfer may be so costly energetically that the mechanism shifts over to the concerted H/D exchange process illustrated in Figure 6, where the ion pair is never formed as a true intermediate.

The above disussion ignores the question of whether, in cases where displacement of ammonia by $\mathrm{A}^{-}$from the acid HA is not observed, the conversion of the amide to the $\mathrm{Ru}-\mathrm{A}$ product is exoergic. Our theoretical calculations (vide infra) suggest that in the case of the reaction with toluene, the conversion of the amide to the benzylruthenium complex may be thermodynamically unfavored. We have tried to explore this question experimentally by treating the potential displacement product $(\mathrm{DMPE})_{2} \mathrm{Ru}(\mathrm{H})\left(\mathrm{CH}_{2} \mathrm{Ph}\right)$, which can be synthesized independently, with ammonia, but this gives no reaction up to temperatures where slow decomposition of the benzyl complex to intractable products sets in. Therefore, there is clearly a kinetic barrier to this transformation, but we do not know if this barrier is high enough to account for the lack of displacement in the "forward" direction. This ambiguity does not exist in the attempted displacement of the ruthenium amide with ${ }^{15} \mathrm{NH}_{3}$, which must be essentially thermoneutral - here it is clear that the lack of displacement must be due to a kinetic rather than a thermodynamic unfavorability.

The lack of ${ }^{15} \mathrm{~N}$ incorporation upon addition of free ${ }^{15} \mathrm{NH}_{3}$ to the amido complex $\mathbf{1}$ also suggests that the $\mathrm{RuNH}_{3}{ }^{+} \cdot \cdot \mathrm{NH}_{2}{ }^{-}$ ion pair does not dissociate easily. Our results contrast with the observation of Schaad and Landis in the similar system, trans-(DMPE) $)_{2} \mathrm{Ru}(\mathrm{H})\left(\mathrm{NHCOCF}_{3}\right){ }^{66}$ Addition of ${ }^{15} \mathrm{NH}_{2} \mathrm{COCF}_{3}$ to this complex does result in ligand exchange, providing support for a facile dissociation of the ligand from the metal center. The only difference between their system and ours is the relative stability of the free anions: $\left[\mathrm{NHCOCF}_{3}\right]^{-}$is a much weaker base than $\mathrm{NH}_{2}{ }^{-}$.

$\mathrm{p} K_{\mathrm{a}}$ Determination and the Nature of the Ion Pair. The equilibrium constant measured $\left(K_{\text {measured }}\right)$ for the conversion of the hydroxo complex $\mathbf{2}$ and fluorene to the fluorenide salt (eqs $4,17) \mathbf{6 a}$ is controlled by the relative $\mathrm{p} K_{\mathrm{a}}$ 's of the ruthenium aquo complex $\mathbf{6} \mathbf{a}$ and that of fluorene. Similarly, the equilibrium constant measured for the reaction of amido complex 1 with triphenylmethane to give triphenylmethide salt $\mathbf{4 h}$ (eqs 11, 16) is controlled by the $\mathrm{p} K_{\mathrm{a}}$ of the ammonia-bound ruthenium complex 4 and the $\mathrm{p} K_{\mathrm{a}}$ of triphenylmethane. Spectroscopic and chemical investigations (see below) showed that the product of the proton transfer is the contact ion pair (CIP) $6 \mathbf{a}$ rather than a solvent-separated ion pair (SSIP) or free ions. Therefore, the equilibrium is most appropriately written as the three component equation shown in eqs 13 and 14.

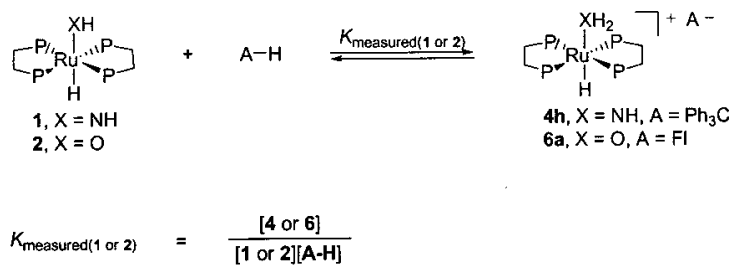

Evidence for the assignment of $\mathbf{4}$ as CIPs was acquired from $\mathrm{UV}$-vis measurements of the reaction solutions and from stereochemical experiments. For example, the $\lambda_{\max }$ of the UVvis spectrum of fluorenide anion is highly dependent upon its environment, the nature of the cation, the temperature of the solution, and the solvent. ${ }^{29}$ Free fluorenide, defined as the fully solvated anion, has $\lambda_{\max }=375 \mathrm{~nm}$ in THF. In fluorenide CIPs, the adsorption band exhibits a hypsochromic shift whose magnitude depends on the size of the cation. For example, lithium fluorenide CIP has $\lambda_{\max }=348 \mathrm{~nm}$, cesium fluorenide CIP has $\lambda_{\max }=364 \mathrm{~nm}$, and tetrabutylammonium fluorenide CIP has $\lambda_{\text {max }}=368 \mathrm{~nm}$. At room temperature, lithium fluorenide exists primarily as a mixture of CIPs and SSIPs, but upon cooling to $-50{ }^{\circ} \mathrm{C}$, the equilibrium favors the SSIP. Large, soft cations such as $\mathrm{Cs}^{+}$are not readily solvated by THF, and their fluorenide salt exists primarily as a CIP in solution. Because $\left[(\mathrm{DMPE})_{2} \mathrm{Ru}(\mathrm{H})\left(\mathrm{NH}_{3}\right)\right]^{+}$is a large, soft cation, its fluorenide salt should also be a CIP. This assumption is supported by its $\lambda_{\max }$ at $368 \mathrm{~nm}$, very close to that of the tetrabutylammonium salt.

On the basis of our evidence for a CIP, the room-temperature equilibrium constants measured between the hydroxo complex, fluorene, and the fluorenide salt $\mathbf{6 a}$ and extrapolated for the amido complex 1, triphenylmethane, and the triphenylmethide salt $4 \mathrm{~h}$ were calculated using the CIP model (eqs 13 and 16). If the extra stabilization due to ion pairing could be ignored, we would conclude that the basicity of the hydroxo complex $\mathbf{2}$ is similar to that of fluorenide and the basicity of amido complex

(66) Schaad, D. R.; Landis, C. R. J. Am. Chem. Soc. 1990, 112, 1628. 
$\mathbf{1}$ is slightly less than that of triphenylmethide. However, this assumption ignores the significant entropic contribution from ion pair formation, and a more accurate estimation of the $\mathrm{p} K_{\mathrm{a}}$ 's of these complexes must take into account the dissociation constants $\left(K_{\text {dissoc }}\right)$ of salts $\mathbf{4 h}$ and $\mathbf{6 a}$ (eqs 15 and 16).

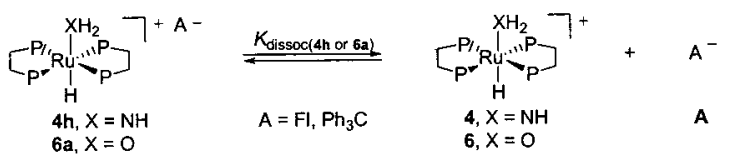

$K_{\text {dissoc(4h or 6a) }}=\frac{[4 \text { or } 6][A]}{[4 h \text { or } 6 a]}$

Because the $\mathrm{p} K_{\mathrm{a}}$ of an acid is defined as the negative log of the equilibrium constant for the dissociation of a proton from the acid, the $\mathrm{p} K_{\mathrm{a}(\mathbf{4} \text { or } 6)}$ of the ammonia complex $\mathbf{4}$ and the aquo complex 6 should be similarly defined (eqs 17 and 18).

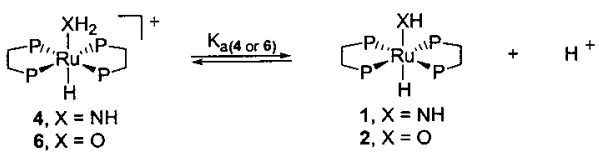

$K_{\mathrm{a}(4 \text { or } 6)}=\frac{[1 \text { or } 2]\left[\mathrm{H}^{+}\right]}{[4 \text { or } 6]} \quad \mathrm{p} K_{\mathrm{a}}=-\log \left(K_{\mathrm{a}(4 \text { or } 6)}\right)$

The $K_{\mathrm{a} 4}$ (or the acid dissociation constant, eq 19) of ammonia complex 4 can be calculated from the ratio of the triphenylmethane acid dissociation constant $\left(K_{\text {acid }}\right)$ to the room-temperature equilibrium constant measured for the conversion of 1 and triphenylmethane to the triphenylmethide complex $\mathbf{4 h}$ $\left(K_{\text {measured1 }}\right)$, and the ion pair dissociation constant of complex 4h ( $K_{\text {dissoc } 4}$, eqs 15 and 16$)$. Similarly, the $K_{\mathrm{a} 6}$ of aquo complex 6 can be calculated from the ratio of the $K_{\text {acid }}$ of fluorene to the room-temperature equilibrium constant measured for the conversion of $\mathbf{2}$ and fluorene to the fluorenide complex $\mathbf{6 a}$ $\left(K_{\text {measured2}}\right)$, and the dissociation constant of complex $\mathbf{6 a}\left(K_{\text {dissoc6 }}\right)$.

$K_{\mathrm{a}(4 \text { or } 6)}=$

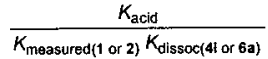

(19)

Streitwieser and co-workers have measured the dissociation constants for a variety of different lithium and cesium salts, including those of fluorenide and triphenylmethide, in the relatively low dielectric constant solvent THF. ${ }^{67}$ These dissociation constants are highly dependent upon the cation and, to a lesser degree, the anion. For example, the dissociation constant $\left(K_{\mathrm{D}}\right)$ for lithium fluorenide in THF at $25.0^{\circ} \mathrm{C}$ is 6.90 $\times 10^{-6} \mathrm{M}$, and the analogous cesium salt has a $K_{\mathrm{D}}$ of $1.49 \times$ $10^{-8} \mathrm{M}, 2$ orders of magnitude smaller. The $K_{\mathrm{D}}$ for the triphenylmethide salts shows similar trends of $2.34 \times 10^{-5}$ and $2.03 \times 10^{-7} \mathrm{M}$ for the lithium and cesium salts, respectively. The difference between the dissociation constants of the cesium and lithium salts is due to the increased ability of THF to solvate the hard lithium ions relative to the soft cesium ions. As stated earlier, our ruthenium cations $\mathbf{4}$ and $\mathbf{6}$ are predicted to be fairly soft and will not be extensively solvated by THF. Therefore, we estimate that the dissociation constant $K_{\mathrm{D}}$ for the salt complexes $\mathbf{4 h}$ and $\mathbf{6 a}$ is on the same order of magnitude as that

(67) Kaufman, M. J.; Gronert, S.; Streitwieser, A. J. Am. Chem. Soc. 1988, $110,2829$. of the corresponding cesium salts of triphenylmethide and fluorenide, respectively, or $10^{-7}$ to $10^{-8}$.

Solving eq 19 for each system using these (admittedly very approximate) dissociation constants yields an estimated $\mathrm{p} K_{\mathrm{a}}$ of the ammonia complex 4 of 23 to 24 and an estimated $\mathrm{p} K_{\mathrm{a}}$ of the aquo complex 6 of 16 to 17 (in THF). Even though the basicity of amido complex $\mathbf{1}$ is, at first, reminiscent of the alkali salts of $\mathrm{NH}_{2}{ }^{-}$, the $\mathrm{p} K_{\mathrm{a}}$ of the cationic ammonia complex is significantly lower than that of free ammonia (41). Ammonia complex 4 is much less acidic than a protonated amine $\left(\mathrm{NH}_{4}{ }^{+}\right.$: 10.5, DMSO, $\mathrm{PhNH}_{3}{ }^{+}:$3.6, DMSO), ${ }^{68}$ indicative of a more polarized $\mathrm{Ru}-\mathrm{N}$ bond as compared to a $\mathrm{C}-\mathrm{N}$ (or $\mathrm{H}-\mathrm{N}$ in the case of $\mathrm{NH}_{4}{ }^{+}$) bond. The $\mathrm{p} K_{\mathrm{a}}$ of aquo complex 2 is similar to that of Mayer's protonated [(phen $\left.)_{2} \mathrm{Mn}(\mu-\mathrm{O})_{2} \mathrm{Mn}(\text { phen })_{2}\right]\left[\mathrm{PF}_{6}\right]_{3}$ $\left(\mathrm{p} K_{\mathrm{a}}=14.6 \pm 0.5, \mathrm{CH}_{3} \mathrm{CN}\right)$ and Pecoraro's protonated [Mn$($ salpn $)(\mu-\mathrm{O})]_{2}$ complex (salpn $=N, N^{\prime}$-bis(salicylidene)-1,3propanediamine, $\left.\mathrm{p} K_{\mathrm{a}}=13.4, \mathrm{CH}_{3} \mathrm{CN}\right) .{ }^{48,69}$ These are larger than the $\mathrm{p} K_{\mathrm{a}}$ of Stack's $\mathrm{Fe}(\mathrm{MeOH})\left(\mathrm{p} K_{\mathrm{a}}=9.7\right.$, methanol) ${ }^{4}$ It is unfortunate that so many of these measurements were made in different solvents. A rigorous comparison of the basicity of these complexes will have to wait until $\mathrm{p} K_{\mathrm{a}}$ studies are carried out under more comparable conditions.

Theoretical Calculations. As mentioned at the end of the Results section, we have carried out several DFT calculations to help us better understand our results. The details are provided in the Supporting Information, but the most important results are summarized here.

We investigated the enthalpies of the reactions between amido complex $\mathbf{1}^{\prime 45}$ or hydroxo complex $\mathbf{2}^{\prime 45}$ and six different substrates $(\mathrm{R}-\mathrm{H})$ : phenol (Scheme 4), phenylacetonitrile (Scheme 2), cyclobutanone (Scheme 2), phenylacetylene (Scheme 2), triphenylmethane (eq 11), and toluene (eqs 7 and 10). Four different reactions of complexes $\mathbf{1}^{\prime}$ or $\mathbf{2}^{\prime}$ with $\mathrm{R}-\mathrm{H}$ were considered: the gas-phase formation of ion pairs (GP-IP), gas-phase formation of infinitely separated ions (ISI) from starting complexes, formation of ISI in THF (ISI-THF), and gas-phase formation of products. In the interest of brevity, the results will only be briefly summarized.

The computational results mirrored information available from experiment. For example, the enthalpy required for the formation of gas-phase ion pairs (GP-IPs) correlated with the gas-phase acidities of the substrate in question (Tables 6 and 7). That is, the reaction between the metal complexes $\mathbf{1}^{\prime 45}$ or $\mathbf{2}^{\prime 45}$ and the stronger gas-phase acids is calculated to be less endothermic than the reactions between the metal complexes and the weaker gas-phase acids. This trend was also followed in the formation of infinitely separated ion pairs (ISIs) and THF-solvated ISIs. The enthalpies of reaction for the formation of ISIs are highly endothermic in the gas phase due to the energetic cost of charge separation. As expected, significant energy $\left(\sim 90 \mathrm{kcal} \mathrm{mol}^{-1}\right)$ was gained upon formation of the GP-IPs from the ISIs. However, only the GP-IPs for the formation of the ion pairs containing enolate $\mathbf{4} \mathbf{b}^{\prime}$, phenylacetylide $\mathbf{4} \mathbf{c}^{\prime}$, and phenolate $\mathbf{4} \mathbf{d}^{\prime}$

(68) The authors would like to advise the reader to view these numbers as qualitative comparison rather than a quantitative comparison. DMSO forms stronger hydrogen bonds with free protons than does THF, and thus the absolute acidity scales in these two solvent systems vary. However, the relative ordering should be the same, see: (a) Kolthoff, I. M.; Chantooni, M. K.; Bhowmik, S. J. Am. Chem. Soc. 1968, 90, 23. (b) Streitwieser, A. Wang, D. Z.; Stratakis, M.; Facchetti, A.; Gareyev, R.; Abbotto, A.; Krom, J. A.; Kilway, K. V. Can. J. Chem. 1998, 76, 765.

(69) Baldwin, M. J.; Pecoraro, V. L. J. Am. Chem. Soc. 1996, 118, 11325. 
Table 6. Calculated Reaction Enthalpies (in $\mathrm{kcal} \mathrm{mol}^{-1}$ ) for the Reaction of Amido Complex 1' with Substrates Listed (See Text) (GPA = Gas-Phase Acidity of Substrate (lit.); GP = Gas Phase; IP = Ion Pair; ISI = Infinitely Separated Ions; Prod. = Products)

\begin{tabular}{lcccccc}
\hline \multicolumn{1}{c}{ substrate } & GPA & $\begin{array}{c}\text { GP- } \\
\text { IP }\end{array}$ & $\begin{array}{c}\text { GP- } \\
\text { ISI }\end{array}$ & $\begin{array}{c}\text { THF- } \\
\text { ISI }\end{array}$ & $\begin{array}{l}\text { GP- } \\
\text { prod. }\end{array}$ & $\begin{array}{l}\text { THF- } \\
\text { prod. }\end{array}$ \\
\hline phenol & $351.6^{a}$ & -22.3 & 67.5 & -8.1 & -17.4 & \\
phenylacetonitrile & $350.7^{b}$ & & 65.3 & -4.2 & -9.2 & \\
cyclobutanone & $367.1^{c}$ & -6.1 & 88.1 & 9.8 & -7.9 & -8.9 \\
phenylacetylene & $370.6^{d}$ & 1.3 & 92 & 13.8 & -21.1 & \\
triphenylmethane & $358.7^{e}$ & & 70.9 & 7.5 & & \\
toluene & $380.6^{f}$ & & 103.8 & 30.2 & 3.5 & \\
\hline
\end{tabular}

${ }^{a}$ DeTuri, V. F.; Ervin, K. M. Int. J. Mass Spectrom. 1998, 175, 123. ${ }^{b}$ Fujio, M.; McIver, R. T.; Taft, R. W. J. Am. Chem. Soc. 1981, 103, 4017. ${ }^{c}$ Brickhouse, M. D.; Squires, R. R. J. Am. Chem. Soc. 1988, 110, 2706. ${ }^{d}$ Bartmess, J. E.; Scott, J. A.; McIver, R. T. J. Am. Chem. Soc. 1979, 101, 6047. ${ }^{e}$ Taft, R. W.; Bordwell, F. G. Acc. Chem. Res. 1988, 21, 463. ${ }^{f}$ Gunion, R. F.; Gilles, M. K.; Polak, M. L.; Lineberger, W. C. Int. J. Mass Spectrom. Ion Processes 1992, 117, 601.

Table 7. Calculated Reaction Enthalpies (in $\mathrm{kcal} \mathrm{mol}^{-1}$ ) for the Reaction of Hydroxo Complex 2' with Substrates Listed (See Text) (GPA = Gas-Phase Acidity of Substrate (lit.); GP = Gas Phase; IP = Ion Pair; ISI = Infinitely Separated Ions; Prod. = Products)

\begin{tabular}{lcccccc}
\hline \multicolumn{1}{c}{ substrate } & GPA & $\begin{array}{c}\text { GP- } \\
\text { IP }\end{array}$ & $\begin{array}{c}\text { GP- } \\
\text { ISI }\end{array}$ & $\begin{array}{c}\text { THF- } \\
\text { ISI }\end{array}$ & $\begin{array}{l}\text { GP- } \\
\text { prod. }\end{array}$ & $\begin{array}{l}\text { THF- } \\
\text { prod. }\end{array}$ \\
\hline phenol & $351.6^{a}$ & & 83.8 & 9.2 & -7.7 & \\
phenylacetonitrile & $350.7^{b}$ & & 81.6 & 13.1 & 0.5 & \\
cyclobutanone & $367.1^{c}$ & & 104.4 & 27 & 1.8 & 1.2 \\
phenylacetylene & $370.6^{d}$ & & 108.3 & 31.2 & -11.3 & \\
triphenylmethane & $358.7^{e}$ & & 87.2 & 24.8 & & \\
toluene & $380.6^{f}$ & & 120.1 & 47.5 & 13.3 & \\
\hline
\end{tabular}

${ }^{a}$ DeTuri, V. F.; Ervin, K. M. Int. J. Mass Spectrom. 1998, 175, 123. ${ }^{b}$ Fujio, M.; McIver, R. T.; Taft, R. W. J. Am. Chem. Soc. 1981, 103, 4017. ${ }^{c}$ Brickhouse, M. D.; Squires, R. R. J. Am. Chem. Soc. 1988, 110, 2706. ${ }^{d}$ Bartmess, J. E.; Scott, J. A.; McIver, R. T. J. Am. Chem. Soc. 1979, 101, 6047. ${ }^{e}$ Taft, R. W.; Bordwell, F. G. Acc. Chem. Res. 1988, 21, 463. ${ }^{f}$ Gunion, R. F.; Gilles, M. K.; Polak, M. L.; Lineberger, W. C. Int. J. Mass Spectrom. Ion Processes 1992, 117, 601 .

were calculated. We were unable to localize the other ammoniabased ion pairs and all of the aquo-based ion pairs; in these cases, all attempts resulted in the proton essentially "jumping" back onto the anion. In solution, the reactions are predicted to be much nearer to thermoneutral.

Interestingly, the enthalpies of displacement-product formation from starting complexes involving amido complex $\mathbf{1}^{\prime}$ were calculated to be exothermic except for the reaction between $\mathbf{1}^{\prime}$ and toluene to form benzyl complex $13^{\prime}$ and ammonia. In contrast, with the ruthenium hydroxo complex $\mathbf{2}^{\prime}$, only the displacement reactions with phenol or phenylacetylene were calculated to be exothermic.

The calculated reaction enthalpies for the formation of displacement products from the starting complexes do not correlate with either the $\mathrm{p} K_{\mathrm{a}}$ or the $\mathrm{BDE}$ of the organic substrates in question. This is in agreement with this group's earlier experimental results in a nickel system. ${ }^{16}$ Thus, the strength of the $\mathrm{Ru}-\mathrm{X}$ bond, as compared to the $\mathrm{R}-\mathrm{H}$ bond, is determined by a combination of both electrostatic and covalent interactions, the balance of which is dependent upon the substrate $(\mathrm{R}-\mathrm{H})$ in question. ${ }^{17}$

In all cases and in agreement with our experimental results, the calculated enthalpies for the reactions involving amido complex 1' were significantly more negative than the reactions involving hydroxo complex $\mathbf{2}^{\prime}$, confirming that $\mathbf{1}^{\prime}$ is more basic than $2^{\prime}$. For example, the enthalpy of ISI formation from starting complexes in the gas phase is $16 \mathrm{kcal} \mathrm{mol}^{-1}$ higher for the reactions involving $\mathbf{2}^{\prime}$ than those involving $\mathbf{1}^{\prime}\left(17 \mathrm{kcal} \mathrm{mol}^{-1}\right.$ in THF). In addition, the gas-phase enthalpy difference in the displacement/product formation reactions between the reactions involving amido complex $\mathbf{1}^{\prime}$ and hydroxo complex $\mathbf{2}^{\prime}$ is -9.7 $\mathrm{kcal} \mathrm{mol}{ }^{-1}$. This is the enthalpy for the reaction of amido complex $\mathbf{1}^{\prime}$ with water to generate hydroxo complex $\mathbf{2}^{\prime}$ and ammonia (eq 20), which experimentally is known to lie far on the side of $\mathbf{2}^{\prime}$, in agreement with the calculations.

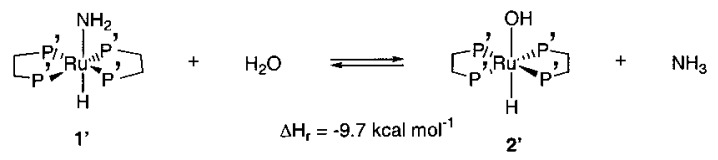

(20)

Because the $\mathrm{N}-\mathrm{H}$ bond of ammonia is $11 \mathrm{kcal} \mathrm{mol}^{-1}$ weaker than the $\mathrm{O}-\mathrm{H}$ bond of water, the driving force for this reaction must be the formation of a more stable $\mathrm{Ru}-\mathrm{O}$ bond as compared to the $\mathrm{Ru}-\mathrm{N}$ bond. This indicates that the $\mathrm{Ru}-\mathrm{O}$ bond is stronger than the $\mathrm{Ru}-\mathrm{N}$ bond by approximately $20 \mathrm{kcal} \mathrm{mol}^{-1}$. This provides the first direct comparison of bond strengths for a late-metal parent-amido complex and its corresponding hydroxo complex. Other studies have been performed that compare the relative bond energies of substituted late metal amido complexes and hydroxo complexes. In all of these studies, the $\mathrm{M}-\mathrm{O}$ bond is considerably stronger (by a magnitude similar to that predicted by our calculations) than the $\mathrm{M}-\mathrm{N}$ bond. ${ }^{1,16}$

\section{Conclusions}

Our study of the properties of the new monomeric late metal parent amido complex trans-(DMPE) $)_{2} \mathrm{Ru}(\mathrm{H})\left(\mathrm{NH}_{2}\right)(\mathbf{1})$ originally focused on its potential to abstract a hydrogen atom from a weak $\mathrm{C}-\mathrm{H}$ bond. This putative one-electron process initially appeared plausible because, in analogy to Stack's Fe ${ }^{\mathrm{III}}$ system, amido complex 1 oxidizes cyclohexadiene (CHD) to benzene. ${ }^{4}$ However, the observed reactivity between $\mathbf{1}$ and an array of $\mathrm{C}-\mathrm{H}$ bonds suggests that the oxidation of CHD occurs via a twoelectron rather than a one-electron process. Deprotonation of sterically encumbered weak acids (such as fluorene and triphenylmethane) by $\mathbf{1}$ generates stable ion pairs containing a cationic ammonia-bound ruthenium complex. Smaller weak acids (such as phenylacetylene, cyclobutanone, alcohols, and amines) are also deprotonated by $\mathbf{1}$ to generate similar ion pairs; however, the transiently generated anion in these intermediates eventually displaces ammonia, yielding covalent ruthenium complexes.

In addition to the reactions observed with weak acids, amido complex 1 also promotes H/D exchange between the protons of its $\mathrm{NH}_{2}$ group and a variety of very weak acids (such as ammonia- $d_{3}$, toluene- $d_{8}$, and propene- $d_{3}$ ). We suggest that these H/D exchange reactions proceed either via the reversible formation of ion pair $\mathbf{4}$ or through a concerted transition state similar to that shown in Figure 6. However, in these cases, no displacement of the ammonia ligand is observed, perhaps because of strong hydrogen bonding in the ion pair that is formed. These reactions provide additional evidence against the intervention of odd-electron processes in this system since the $\mathrm{H} / \mathrm{D}$ exchange rate correlates more strongly with the $\mathrm{p} K_{\mathrm{a}}$ of the carbon acid than with the bond dissociation energy of the $\mathrm{C}-\mathrm{H}$ bond in question.

The relative basicity of our amido complex $\mathbf{1}$ was at first reminiscent of that of the very strong base, sodium amide. 
However, the contrast between amido complex $\mathbf{1}$ and sodium amide is marked by their differing reactivity toward benzene: $\mathrm{NaNH}_{2}$ undergoes H/D exchange with benzene, while 1 does not. ${ }^{56}$ We estimate the $\mathrm{p} K_{\mathrm{a}}$ of the ammonia complex 4 to be approximately 23 to 24; thus, $\mathbf{1}$ is a much stronger base than are ordinary alkylamines. There is much more negative charge on nitrogen than is observed in compounds with a $\mathrm{C}-\mathrm{N}$ bond, but less than that observed in alkali metal salts. At present, we do not know the cause of the high basicity of $\mathbf{1}$. Two possible explanations are the highly polar nature of the $\mathrm{Ru}-\mathrm{N} \sigma$-bond and $\mathrm{d} \pi-\mathrm{p} \pi$ repulsion between the filled d-orbitals on ruthenium and the nitrogen lone pair orbital. ${ }^{14,17}$ Further work will be required to distinguish these two effects.

The calculations on our model systems amido complex $\mathbf{1}^{\prime}$ and hydroxo complex $\mathbf{2}^{\prime}$ correlated well with our experimental results. The enthalpy of ion formation (either as ion pairs or infinitely separated ions) from $\mathbf{1}^{\prime}$ or $\mathbf{2}^{\prime}$ and the weakest acids was substantially larger than the enthalpy of ion formation from $\mathbf{1}^{\prime}$ or $\mathbf{2}^{\prime}$ and the stronger acids. Accordingly, the enthalpy of ISI formation was much greater than the enthalpy of IP formation. The calculations predict that the formation of benzyl complex 13' and ammonia from the amido complex $\mathbf{1}^{\prime}$ and toluene is endothermic in the gas phase. Whether this is actually the case, or whether $\mathbf{1 3}$ is not formed because of the high barrier of ion pair dissociation, is arguable, and our experimental results do not provide enough evidence to exclude either hypothesis.

\section{Experimental Section}

General Comments. All manipulations were carried out under inert atmosphere or by using standard Schlenk or vacuum line techniques unless noted otherwise. The ${ }^{1} \mathrm{H}$ and ${ }^{13} \mathrm{C}$ NMR spectra were obtained on Bruker 300 and $400 \mathrm{MHz}$ Fourier transform spectrometers with commercial Bruker AMX series interfaces or a Bruker $500 \mathrm{MHz}$ Fourier transform spectrometer with a commercial Bruker DRX series interface. The latter instrument was used in the equilibrium experiments, and the thermocouple was calibrated with either neat methanol or neat ethylene glycol prior to each experiment.

trans-(DMPE) ${ }_{2} \mathrm{Ru}(\mathrm{H})\left(\mathrm{NH}_{2}\right)(\mathbf{1})$, trans-(DMPE) $)_{2} \mathrm{Ru}(\mathrm{H})(\mathrm{OH})(\mathbf{2})$, and $(\mathrm{DMPE})_{2} \mathrm{Ru}(\mathrm{H})_{2}(\mathbf{3})$ were prepared by literature methods. ${ }^{19,30,61,70}$ All other reagents were purchased from commercial vendors, checked for purity, and used without further purification unless otherwise noted. Fluorene and triphenylmethane were purified via sublimation. Liquids were degassed using three freeze-pump-thaw cycles and dried over $4 \AA$ activated molecular sieves or passed through an activated alumina column. Solids were stored in an inert atmosphere box. Toluene, benzene, pentane, and hexanes (UV grade, alkene free) were passed through a column of activated alumina (A1, $12 \times 32$, Purifry) under nitrogen pressure and sparged with nitrogen prior to use. ${ }^{71}$ Diethyl ether and tetrahydrofuran were distilled from purple sodium/benzophenone ketyl under nitrogen. Benzene- $d_{6}$ and toluene- $d_{8}$ were degassed by three freeze-pump-thaw cycles, placed over $4 \AA$ activated molecular sieves, and filtered through glass-fiber filter paper prior to use. THF- $d_{8}$ was vacuum transferred from sodium/benzophenone ketyl and stored under inert atmosphere.

[trans-(DMPE) $\left.)_{2} \mathbf{R u}(\mathbf{H})\left(\mathbf{N H}_{3}\right)\right]\left[\mathbf{C}_{13} \mathbf{H}_{9}\right]$ (4a). A vial was charged with trans-(DMPE $)_{2} \mathrm{Ru}(\mathrm{H})\left(\mathrm{NH}_{2}\right)\left(37.5 \mathrm{mg}, 9.0 \times 10^{-5} \mathrm{~mol}\right)$ and $10 \mathrm{~mL}$ of pentane. To this was added a solution consisting of fluorene $(14.9 \mathrm{mg}$, $9.0 \times 10^{-5} \mathrm{~mol}$ ) and $2 \mathrm{~mL}$ of pentane. A yellow-orange precipitate formed immediately. The volatile material was removed in vacuo, and the product was washed with $5 \mathrm{~mL}$ of pentane. The residue was

(70) Field, L. D.; Hambley, T. W.; Yau, B. C. K. Inorg. Chem. 1994, 33, 2010 (71) Alaimo, P. J.; Peters, D. W.; Arnold, J.; Bergman, R. G. J. Chem. Educ. 2001, 78, 64 . dissolved in $1 \mathrm{~mL}$ of THF. After layering with $1 \mathrm{~mL}$ of pentane, the solution was cooled to $-30{ }^{\circ} \mathrm{C}$ to produce orange crystals of $4 \mathbf{a}(37.5$ $\left.\mathrm{mg}, 6.4 \times 10^{-5} \mathrm{~mol}, 72 \%\right) .{ }^{1} \mathrm{H}$ NMR $\left(d_{8}\right.$-THF $): \delta 7.82(\mathrm{~d}, 2 \mathrm{H}, J=$ 7.6, $\operatorname{Ar} H), 7.26(\mathrm{~d}, 2 \mathrm{H}, J=8.4, \operatorname{Ar} H), 6.77(\mathrm{t}, 2 \mathrm{H}, J=7.2, \operatorname{Ar} H), 6.40$ (t, $2 \mathrm{H}, J=7.0 \mathrm{~Hz}, \operatorname{Ar} H$ ), 5.94 (s, 1H, ArH), 1.3 (br m, 8H, DMPE), 1.2 (s, 12H, DMPE), 0.9 (s, 12H, DMPE), -0.6 (br, 3H, $\mathrm{NH}_{3}$ ), -20.34 (qn, $1 \mathrm{H}, J=21.2, \mathrm{Ru} H) .{ }^{13} \mathrm{C}\left\{{ }^{1} \mathrm{H}\right\} \mathrm{NMR}\left(d_{8}\right.$-THF): $\delta 138.2$ (quat), $123.4(\mathrm{CH}), 119.8(\mathrm{CH}), 119.5(\mathrm{CH}), 117.0(\mathrm{CH}), 108.8$ (quat), 83.6 $(\mathrm{CH}), 31.3$ (m, DMPE), 22.7 (m, DMPE), 14.2 (m, DMPE). ${ }^{31} \mathrm{P}\left\{{ }^{1} \mathrm{H}\right\}$ NMR ( $d_{8}$-THF): $\delta 46.41$. IR (Nujol): $3331,3272,3044,3027,1916$, $1571,1467,1440,1423,1321,1284,1233,1221,1107,982,937,925$, 888, 840, 794, 743, 731, 711, $647 \mathrm{~cm}^{-1}$. Anal. Calcd for $\mathrm{RuP}_{4-}$ $\mathrm{NC}_{25} \mathrm{H}_{45}$ : C, 51.36; H, 7.76; N, 2.40. Found: C, 51.53; H, 7.40; N, 2.32 .

[trans-(DMPE) $\left.)_{2} \mathbf{R u}(\mathbf{H})\left(\mathbf{N H}_{3}\right)\right]\left[\mathbf{O C}_{6} \mathbf{H}_{5}\right](\mathbf{4 d})$. To solution consisting of trans-(DMPE) $)_{2} \mathrm{Ru}(\mathrm{H})\left(\mathrm{NH}_{2}\right)\left(125 \mathrm{mg}, 2.99 \times 10^{-4} \mathrm{~mol}\right)$ and $15 \mathrm{~mL}$ of hexanes was added a solution consisting of phenol $(27.8 \mathrm{mg}, 2.95$ $\left.\times 10^{-4} \mathrm{~mol}\right)$ and $5 \mathrm{~mL}$ of hexanes. A powdery white precipitate formed. The volatile materials were removed under reduced pressure, and the white solid was stored at $-30{ }^{\circ} \mathrm{C} .{ }^{1} \mathrm{H}$ NMR (THF- $d_{8}, 193 \mathrm{~K}$ ): $\delta 6.67$ (t, $2 \mathrm{H}, J=7.3, \operatorname{Ar} H$ ), 6.02 (d, $2 \mathrm{H}, J=7.5, \operatorname{Ar} H$ ), 5.84 (t, $1 \mathrm{H}, J=6.5$, $\mathrm{ArH}$ ), 2.53 (s, 3H, NH $H_{3}$ ), 1.67 (s, 4H, DMPE), 1.59 (s, 12H, DMPE), 1.46 (s, 4H, DMPE), 1.28 (s, 12H, DMPE), -19.48 (qn, $1 \mathrm{H}, J_{\mathrm{HP}}=$ 20.8, Ru- $H$ ). ${ }^{13} \mathrm{C}\left\{{ }^{1} \mathrm{H}\right\}$ NMR (THF- $d_{8}, 203 \mathrm{~K}$ ): $\delta 172.6$ (quat), 129.5 $(\mathrm{CH}), 121.0(\mathrm{CH}), 107.8(\mathrm{CH}), 30.8$ (m, DMPE), $23.2(\mathrm{~m}, \mathrm{DMPE})$, 14.5 (m, DMPE). ${ }^{31} \mathrm{P}\left\{{ }^{1} \mathrm{H}\right\}$ NMR (THF- $\left.d_{8}\right): \delta 47.7$. IR (Nujol): 3351, $3312,3223,2658,2551,2480,2397,2302,2235,2147,1901,1798$, $1636,1578,1546,1537,1483,1426,1329,1285,1240,1217,1154$, $1141,1124,1085,1059,1012,979,929,890,923,938,820,795 \mathrm{~cm}^{-1}$. Anal. Calcd for $\mathrm{RuP}_{4} \mathrm{NOC}_{18} \mathrm{H}_{41}$ : C, 42.19; H, 8.06; N, 2.73. Found: C, 42.47; H, 8.15; N, 3.02 .

[trans-(DMPE) $\left.)_{2} \mathbf{R u}(\mathbf{H})\left(\mathbf{N H}_{3}\right)\right]\left[\mathrm{OC}_{6} \mathbf{H}_{4} \mathrm{Me}\right](\mathbf{4 e})$. A vial was charged with trans-(DMPE) $)_{2} \mathrm{Ru}(\mathrm{H})\left(\mathrm{NH}_{2}\right)\left(217 \mathrm{mg}, 5.19 \times 10^{-3} \mathrm{~mol}\right)$ and 0.5 $\mathrm{mL}$ of THF. To it was added a solution consisting of $p$-cresol (55.3 $\mathrm{mg}, 5.11 \times 10^{-4} \mathrm{~mol}$ ) and $0.5 \mathrm{~mL}$ of THF. The resulting solution was layered with $2 \mathrm{~mL}$ of pentane and placed into a $-30{ }^{\circ} \mathrm{C}$ freezer for 1 month to give pale-yellow crystals of $4 \mathbf{e}$ in $59 \%$ yield $(159 \mathrm{mg}, 3.01$ $\left.\times 10^{-3} \mathrm{~mol}\right) .{ }^{1} \mathrm{H}$ NMR $\left(\right.$ THF- $\left.d_{8}, 203 \mathrm{~K}\right): \delta 6.50(\mathrm{~d}, 2 \mathrm{H}, J=7.5, \mathrm{Ar} H)$, $5.93(\mathrm{~d}, 2 \mathrm{H}, J=7.5, \operatorname{Ar} H), 2.55$ (s, 3H, NH $\left.H_{3}\right), 1.68$ (s, 4H, DMPE), 1.43 (s, 12H, DMPE), 1.37 (s, 4H, DMPE), 1.28 (s, 12H, DMPE), -19.45 (s, $1 \mathrm{H}, \mathrm{Ru}-H) .{ }^{13} \mathrm{C}\left\{{ }^{1} \mathrm{H}\right\} \mathrm{NMR}$ (THF- $d_{8}, 223 \mathrm{~K}$ ): $\delta 170.5$ (quat), $130.1(\mathrm{CH}), 120.3(\mathrm{CH}), 114.8$ (quat), 31.1 (m, DMPE), $23.4(\mathrm{~m}$, DMPE), $21.3\left(\mathrm{CH}_{3}\right), 14.5$ (DMPE). ${ }^{13} \mathrm{P}\left\{{ }^{1} \mathrm{H}\right\}$ NMR (THF- $\left.d_{8}, 298 \mathrm{~K}\right)$ : $\delta$ 47.7. IR (Nujol): 3357, 3295, 3282, 3184, 3042, 2854, 2812, 2724 , $2640,2545,2853,2317,2263,2149,2070,1982,1878,1818,1734$, 1650, 1597, 1536, 1494, 1425, 1322, 1302, 1289, 1231, 1158, 1121, $1095,1085,990,930,913,887,838,825,797 \mathrm{~cm}^{-1}$. Anal. Calcd for $\mathrm{RuP}_{4} \mathrm{NOC}_{19} \mathrm{H}_{43}$ : C, 43.34; H, 8.23; N, 2.66. Found: C, 43.70; H, 8.33; $\mathrm{N}, 2.58$.

Generation, Spectroscopic Characterization, and Isolation in Crude Form of Ion Pair Salts 4b, 4c, 4f, and 4g: General Procedure. A vial was charged with trans-(DMPE) $)_{2} \mathrm{Ru}(\mathrm{H})\left(\mathrm{NH}_{2}\right)(107$ $\left.\mathrm{mg}, 2.54 \times 10^{-4} \mathrm{~mol}\right)$ and $8 \mathrm{~mL}$ of hexanes. To it was added a solution consisting of phenylacetylene $\left(25.9 \mathrm{mg}, 2.54 \times 10^{-4} \mathrm{~mol}\right)$ and $1 \mathrm{~mL}$ of hexanes. A white powder precipitated from solution, and the volatile material was removed in vacuo. Pure material could not be obtained because some final covalent product formed in each case during this procedure, as ascertained by NMR spectroscopy.

[trans-(DMPE) $\left.)_{2} \mathbf{R u}(\mathbf{H})\left(\mathbf{N H}_{3}\right)\right]\left[\mathbf{C}_{4} \mathbf{H}_{5} \mathbf{O}\right](\mathbf{4 b}) .{ }^{1} \mathrm{H}$ NMR $\left(\mathrm{THF}-d_{8}, 222\right.$ $\mathrm{K}): \delta 3.38(\mathrm{~s}, 1 \mathrm{H}, \mathrm{CHC}(\mathrm{O})), 2.38\left(\mathrm{~s}, 3 \mathrm{H}, \mathrm{NH}_{3}\right), 2.13(\mathrm{~s}, 2 \mathrm{H}, \mathrm{C}(\mathrm{O})-$ $\mathrm{CH}_{2}$ ), 1.97 (br m, 4H, DMPE), 1.71 (s, 2H, $\mathrm{CH}_{2} \mathrm{CHC}(\mathrm{O}) \mathrm{CH}_{2}$ ), 1.54 (s, 12H, DMPE), 1.46 (br m, 4, DMPE), 1.33 (s, 12H, DMPE), -19.4 (qn, $1, J=25, \mathrm{Ru} H) .{ }^{13} \mathrm{C}\left\{{ }^{1} \mathrm{H}\right\} \mathrm{NMR}\left(\mathrm{THF}-d_{8}, 222 \mathrm{~K}\right): 166.48(C \mathrm{O})$, $82.40(\mathrm{CH}), 39.35\left(\mathrm{CH}_{2}\right), 31.16\left(\mathrm{qn}, J_{\mathrm{C}-\mathrm{P}}=51, \mathrm{DMPE}\right), 23.45(\mathrm{~m}$, DMPE), $19.50\left(\mathrm{CH}_{2}\right), 14.96$ (m, DMPE). ${ }^{31} \mathrm{P}\left\{{ }^{1} \mathrm{H}\right\}$ NMR $\left(d_{8}\right.$-THF, 25 
$\left.{ }^{\circ} \mathrm{C}\right): \delta 40.38$. IR (Nujol): 3353, 3296, 1872, 1643, 1581, 1458, 1425, 1378, 1284, 1159, 1121, 1078, 981, 912, 889, 841, 794, 729, 707, 644.

$\left.[\text { trans-(DMPE) })_{2} \mathbf{R u}(\mathbf{H})\left(\mathbf{N H}_{3}\right)\right][\mathbf{C C P h}](\mathbf{4 c}) .{ }^{1} \mathrm{H}$ NMR $\left(\mathrm{THF}-d_{8}, 222\right.$ $\mathrm{K}): \delta 7.07(\mathrm{~d}, 1 \mathrm{H}, J=7.5, \operatorname{Ar} H), 7.06(\mathrm{t}, 1 \mathrm{H}, J=7.3 \operatorname{Ar} H), 7.04(\mathrm{~d}$, $1 \mathrm{H}, J=7.5 \mathrm{Ar} H), 7.03(\mathrm{t}, 1 \mathrm{H}, J=7.5 \mathrm{ArH}), 6.94(\mathrm{t}, 1 \mathrm{H}, J=8.0$ $\mathrm{ArH}$ ), 2.50 (s, 3H, $\mathrm{NH}_{3}$ ), 2.36 (br s, 4H, DMPE), 1.68 (s, 12H, DMPE), 1.48 (br s, 4H, DMPE), 1.36 (s, 12H, DMPE), -19.19 (qn, 1H, $J=$ 20.8, RuH $).{ }^{13} \mathrm{C}\left\{{ }^{1} \mathrm{H}\right\} \mathrm{NMR}$ (THF- $\left.d_{8}, 222 \mathrm{~K}\right): \delta 133.20(\mathrm{Ru}-\mathrm{CC})$, $131.42(\mathrm{CH}), 128.27(\mathrm{CH}), 123.71(\mathrm{CH}), 109.36$ (ipso-C), 31.67 (m, DMPE), 23.30 (DMPE), 16.78 (DMPE). ${ }^{31} \mathrm{P}\left\{{ }^{1} \mathrm{H}\right\} \mathrm{NMR}$ (THF- $d_{8}, 25$ $\left.{ }^{\circ} \mathrm{C}\right): \delta$ 48.5. IR (Nujol): 3361, 3256, 3068, 2347, 2236, 2140, 1994, 1920, 1885, 1636, 1561, 1589, 1479, 1424, 1299, 1284, 1266, 1234, 1183, 1168, 1121, 1083, 1065, 1025, 932, 914, 889, 842, $798 \mathrm{~cm}^{-1}$.

$\left.[\text { trans-(DMPE) })_{2} \mathbf{R u}(\mathbf{H})\left(\mathbf{N H}_{3}\right)\right][\mathbf{M e O}](\mathbf{4 f}) .{ }^{1} \mathrm{H}$ NMR $\left(\mathrm{THF}-d_{8}, 193\right.$ $\mathrm{K}): 3.73\left(\mathrm{~s}, 3 \mathrm{H}, \mathrm{CH}_{3} \mathrm{O}\right), 3.31\left(\mathrm{~s}, 3 \mathrm{H}, \mathrm{NH}_{3}\right), 2.11$ (s, 4H, DMPE), 1.63 (s, 12H, DMPE), 1.45 (s, 4H, DMPE), 1.33 (s, 12H, DMPE). ${ }^{13} \mathrm{C}\left\{{ }^{1} \mathrm{H}\right\}$ NMR (THF- $\left.d_{8}, 223 \mathrm{~K}\right): \delta 57.5\left(\mathrm{CH}_{3} \mathrm{O}\right), 31.6(\mathrm{~m}, \mathrm{DMPE}), 32.6(\mathrm{~m}$, DMPE), 14.1 (m, DMPE). ${ }^{31} \mathrm{P}\left\{{ }^{1} \mathrm{H}\right\}$ NMR (THF- $\left.d_{8}\right): \delta$ 45.2. IR (Nujol): 2653, 2518, 1869, 1662, 1423, 1320, 1291, 1234, 1085, 934, $912,888,841,798 \mathrm{~cm}^{-1}$.

[trans-(DMPE) $\left.)_{2} \mathbf{R u}(\mathbf{H})\left(\mathbf{N H}_{3}\right)\right]\left[\mathbf{N H C}_{6} \mathbf{H}_{5}\right](\mathbf{4 g}) .{ }^{1} \mathrm{H}$ NMR $\left(\mathrm{C}_{6} \mathrm{D}_{6}, 213\right.$ $\mathrm{K}): \delta 6.42(\mathrm{t}, 2 \mathrm{H}, J=7.5, \operatorname{Ar} H), 5.81(\mathrm{~d}, 2 \mathrm{H}, J=7.5, \operatorname{Ar} H), 5.43(\mathrm{t}$, $1 \mathrm{H}, J=6.8, \operatorname{Ar} H), 2.92\left(\mathrm{~s}, 3 \mathrm{H}, \mathrm{NH}_{3}\right), 1.84$ (m, 4H, DMPE), 1.40 (m, 4H, DMPE), 1.35 (s, 12H, DMPE), 1.29 (s, 12H, DMPE), -19.34 (qn, $1 \mathrm{H}, J=21.1) .{ }^{13} \mathrm{C}\left\{{ }^{1} \mathrm{H}\right\}$ NMR (THF- $d_{8}, 223 \mathrm{~K}$ ): $\delta 165.3$ (quat), 129.4 $(\mathrm{CH}), 115.7(\mathrm{CH}), 103.8(\mathrm{CH}), 31.2(\mathrm{~m}, \mathrm{DMPE}), 25.2$ (m, DMPE), 15.5 (m, DMPE). ${ }^{31} \mathrm{P}\left\{{ }^{1} \mathrm{H}\right\}$ NMR (THF- $\left.d_{8}\right): \delta 44.8$. IR (Nujol): 3235 , 3182, 1902, 1596, 1487, 1442, 1422, 1300, 1165, 1091, 1079, 990, 934, 919, 889, 837, $813 \mathrm{~cm}^{-1}$.

$\left.[\text { trans-(DMPE) })_{2} \mathbf{R u}(\mathbf{H})\left(\mathbf{N H}_{3}\right)\right]\left[\mathbf{P h}_{3} \mathbf{C}\right](\mathbf{4 h})$. A vial was charged with trans-(DMPE) $)_{2} \mathrm{Ru}(\mathrm{H})\left(\mathrm{NH}_{2}\right)\left(21.5 \mathrm{mg}, 5.15 \times 10^{-5} \mathrm{~mol}\right)$, triphenylmethane $\left(12.5 \mathrm{mg}, 5.15 \times 10^{-5} \mathrm{~mol}\right)$, and $0.5 \mathrm{~mL}$ of THF- $d_{8}$. Complex 4h is observed in solution in equilibrium with $\mathbf{1}$ and triphenylmethane (see text); therefore, we were unable to cleanly isolate $\mathbf{4 h}$ for full characterization and could only obtain low-temperature NMR evidence for its existence. ${ }^{1} \mathrm{H}$ NMR $\left(d_{8}\right.$-THF, $\left.202 \mathrm{~K}\right): \delta 7.35(\mathrm{~d}, 6 \mathrm{H}, J=8.0$, $\operatorname{Ar} H$ ), 6.50 (t, 6H, $J=7.5, \operatorname{Ar} H$ ), 5.94 (t, 3H, $J=7, \operatorname{Ar} H$ ), 1.65 (br m, 4H, DMPE), 1.54 (br m, 4H, DMPE), 1.36 (s, 12H, DMPE), 1.29 (s, 12H, DMPE), 0.08 (br s, 3H, NH $H_{3}$ ), -19.0 (qn, $1 \mathrm{H}, J=20 \mathrm{H}, \mathrm{Ru} H$ ). ${ }^{13} \mathrm{C}\left\{{ }^{1} \mathrm{H}\right\}$ NMR $\left(d_{8}\right.$-THF, $\left.202 \mathrm{~K}\right): \delta 150.0$ (quat), $128.4(C \mathrm{H}), 124.2$ $(\mathrm{CH}), 113.3(\mathrm{CH}), 91.4$ (quat), 31.3 (m, DMPE), 22.9 (m, DMPE), 14.0 (m, DMPE). ${ }^{31} \mathrm{P}\left\{{ }^{1} \mathrm{H}\right\}$ NMR $\left(d_{8}\right.$-THF, $\left.202 \mathrm{~K}\right): \delta 45.1$.

[trans-(DMPE) $\left.)_{2} \mathbf{R u}(\mathbf{H})\left(\mathbf{O H}_{2}\right)\right]\left[\mathbf{C}_{13} \mathbf{H}_{9}\right](\mathbf{6 a})$. A vial was charged with trans-(DMPE) $)_{2} \mathrm{Ru}(\mathrm{H})(\mathrm{OH})\left(20.1 \mathrm{mg}, 4.8 \times 10^{-5} \mathrm{~mol}\right)$, fluorene $(8.0$ $\left.\mathrm{mg}, 4.8 \times 10^{-5} \mathrm{~mol}\right)$, and $0.5 \mathrm{~mL}$ of THF- $d_{8}$. Complex $\mathbf{6 a}$ is observed in solution in equilibrium with $\mathbf{2}$ and triphenylmethane (see text); therefore, we were unable to cleanly isolate $\mathbf{6 a}$ for full characterization and could only obtain low-temperature NMR evidence for its existence. ${ }^{1} \mathrm{H}$ NMR $\left(d_{8}\right.$-THF, $\left.203 \mathrm{~K}\right): \delta 7.87(\mathrm{~d}, 2 \mathrm{H}, J=7.5, \operatorname{Ar} H), 7.31(\mathrm{~d}, 2 \mathrm{H}$, $J=7.2, \operatorname{Ar} H), 6.82(\mathrm{t}, 2 \mathrm{H}, J=7.8, \operatorname{Ar} H), 6.36(\mathrm{t}, 2 \mathrm{H}, J=6.9, \operatorname{Ar} H)$, 5.97 (s, 1H, ArH), 1.62 (br m, 4H, DMPE), 1.46 (br m, H, DMPE), 1.30 (br, 24H, DMPE), -23.4 (br, $1 \mathrm{H}, \mathrm{Ru} H) .{ }^{13} \mathrm{C}\left\{{ }^{1} \mathrm{H}\right\}$ NMR $\left(d_{8}\right.$-THF, $203 \mathrm{~K}$ ): $\delta 150.1$ (quat), 145.1 (quat), $128.4(\mathrm{CH}), 127.2(\mathrm{CH}), 124.3$ $(\mathrm{CH}), 113.3(\mathrm{CH}), 91.4(\mathrm{CH}), 31.5$ (DMPE), 32.2 (m, DMPE), 14.0 (m, DMPE). ${ }^{31} \mathrm{P}\left\{{ }^{1} \mathrm{H}\right\}$ NMR $\left(d_{8}\right.$-THF, $\left.203 \mathrm{~K}\right): \delta 45.3$.

trans-(DMPE) $)_{2} \mathbf{R u}(\mathbf{H})(\mathbf{C C P h})$ (7). A vial was charged with 80.8 $\mathrm{mg}\left(1.93 \times 10^{-4} \mathrm{~mol}\right)$ of trans-(DMPE) $)_{2} \mathrm{Ru}(\mathrm{H})\left(\mathrm{NH}_{2}\right)$ and $2 \mathrm{~mL}$ of THF. To it was added a solution consisting of phenylacetylene $(19.5 \mathrm{mg}$, $\left.1.91 \times 10^{-4} \mathrm{~mol}\right)$ and $1 \mathrm{~mL}$ of THF. The volatile materials were removed under reduced pressure after $8 \mathrm{~h}$ at $25^{\circ} \mathrm{C}$. The remaining residue was dissolved in $1 \mathrm{~mL}$ of toluene and cooled to $-30{ }^{\circ} \mathrm{C}$ to give peach crystals in $71 \%$ yield $\left(68.2 \mathrm{mg}, 1.34 \times 10^{-4} \mathrm{~mol}\right) .{ }^{1} \mathrm{H}$ NMR $\left(\mathrm{C}_{6} \mathrm{D}_{6}\right): \delta 7.47(\mathrm{~d}, 2 \mathrm{H}, J=7), 7.16(\mathrm{t}, 2 \mathrm{H}, J=7.8), 6.95(\mathrm{t}, 1 \mathrm{H}, J=$ 7.5), $1.50(\mathrm{~s}, 12 \mathrm{H}), 1.49(\mathrm{~m}, 4 \mathrm{H}), 1.29(\mathrm{~m}, 4 \mathrm{H}), 1.24(\mathrm{~s}, 12 \mathrm{H}),-11.95$ (qn, $1 \mathrm{H}, J=21.5) .{ }^{31} \mathrm{P}\left\{{ }^{1} \mathrm{H}\right\}$ NMR: $\delta 45.6$ (s). lit. ${ }^{30}{ }^{1} \mathrm{H}$ NMR $\left(\mathrm{C}_{6} \mathrm{D}_{6}\right)$ : $\delta 7.47$ (d, 2H, $J=6.9$ ), 7.18 (s, 2H), 6.95 (t, 2H, $J=7.4$ ), 1.50 (s,
$12 \mathrm{H}), 1.51(\mathrm{~m}, 4 \mathrm{H}), 1.29(\mathrm{~m}, 4 \mathrm{H}), 1.24(\mathrm{~s}, 12 \mathrm{H}),-11.95$ (qn, $1 \mathrm{H}, J=$ 20.0). ${ }^{13} \mathrm{P}\left\{{ }^{1} \mathrm{H}\right\}$ NMR $\left(\mathrm{C}_{6} \mathrm{H}_{6}\right): \delta 45.5(\mathrm{~s})$.

trans-(DMPE) $)_{2} \mathbf{R u}(\mathbf{H})(\mathbf{C C M e})(8)\left(\right.$ Method A). Allene $\left(7.99 \times 10^{-4}\right.$ mol) was condensed onto a frozen solution consisting of trans$(\mathrm{DMPE})_{2} \mathrm{Ru}(\mathrm{H})\left(\mathrm{NH}_{2}\right)\left(333 \mathrm{mg}, 7.97 \times 10^{-4} \mathrm{~mol}\right)$ and $30 \mathrm{~mL}$ of toluene. The solution was warmed to room temperature and allowed to stir for $3 \mathrm{~d}$, after which time the volatile materials were removed in vacuo. The residue was dissolved in a minimal amount of diethyl ether ( 2 $\mathrm{mL}$ ). The resulting solution was filtered through glass fiber and cooled to $-30{ }^{\circ} \mathrm{C}$ for $3 \mathrm{~d}$ to give yellow needles of $\mathbf{8}(257 \mathrm{mg}, 73 \%) .{ }^{1} \mathrm{H}$ NMR $\left(\mathrm{C}_{6} \mathrm{D}_{6}\right): \delta 2.16\left(\mathrm{~s}, 3 \mathrm{H}, \mathrm{CCH}_{3}\right), 1.56(\mathrm{~m}, 4 \mathrm{H}, \mathrm{DMPE}), 1.54(\mathrm{~s}$, 12H, DMPE), 1.32 (m, 4H, DMPE), 1.27 (s, 12H, DMPE), -12.46 (qn, $1 \mathrm{H}, J=21, \mathrm{Ru} H$ ). ${ }^{13} \mathrm{C} \mathrm{NMR}\left(\mathrm{C}_{6} \mathrm{D}_{6}\right): \delta 107.67$ (qn, $J=45.0$, RuCC), 97.00 (RuCC), 32.38 (qn, $J=55.4$, DMPE), 24.61 (qn, $J=$ 28.3, DMPE), 17.92 (qn, $J=25.8, \mathrm{D} M \mathrm{PE}), 7.84\left(\mathrm{CCH}_{3}\right) .{ }^{31} \mathrm{P} \mathrm{NMR}$ $\left(\mathrm{C}_{6} \mathrm{D}_{6}\right): \delta 46.32(\mathrm{~d}, J=10)$. IR (Nujol): 2715, 2395, 2348, 2079, $1731,1420,1291,1275,1232,1119,1073,991,935,888,839,794$ $\mathrm{cm}^{-1}$. Anal. Calcd for $\mathrm{RuP}_{4} \mathrm{C}_{15} \mathrm{H}_{36}: \mathrm{C}, 40.82 ; \mathrm{H}, 8.22$. Found: $\mathrm{C}, 41.15$; $\mathrm{H}, 8.26$.

trans-(DMPE) $)_{2} \mathbf{R u}(\mathrm{H})(\mathrm{CCMe})(\mathbf{8})($ Method B). Propyne $(7.79 \times$ $\left.10^{-4} \mathrm{~mol}\right)$ was condensed onto a frozen solution consisting of trans$(\mathrm{DMPE})_{2} \mathrm{Ru}(\mathrm{H})\left(\mathrm{NH}_{2}\right)\left(82.5 \mathrm{mg}, 1.97 \times 10^{-4} \mathrm{~mol}\right)$ and $10 \mathrm{~mL}$ of toluene. The solution was warmed to room temperature and allowed to stir for $3 \mathrm{~d}$, after which time the volatile materials were removed under reduced pressure. The tan residue was dissolved in $1 \mathrm{~mL}$ of toluene, and the resulting solution was cooled to $-30{ }^{\circ} \mathrm{C}$ for $1 \mathrm{~d}$ to give yellow crystals of 7 in $64 \%$ yield $\left(55.9 \mathrm{mg}, 1.27 \times 10^{-4} \mathrm{~mol}\right)$. The spectroscopic data for this material were identical to those obtained from Method A.

trans-(DMPE) $)_{2} \mathbf{R u}(\mathbf{H})(\mathbf{N C C}(\mathbf{H}) \mathbf{P h})(\mathbf{9 a})$. A vial was charged with trans-(DMPE) $)_{2} \mathrm{Ru}(\mathrm{H})\left(\mathrm{NH}_{2}\right)\left(68.5 \mathrm{mg}, 1.64 \times 10^{-4} \mathrm{~mol}\right)$ and $5 \mathrm{~mL}$ of toluene. To it was added a solution consisting of phenylacetonitrile $\left(19.7 \mathrm{mg}, 1.68 \times 10^{-4} \mathrm{~mol}\right)$ and $5 \mathrm{~mL}$ of toluene. The solution turned yellow after $2 \mathrm{~d}$ at $25^{\circ} \mathrm{C}$. The volatile materials were removed under reduced pressure. The yellow residue was dissolved into $4 \mathrm{~mL}$ of THF, and the resulting solution was layered with $8 \mathrm{~mL}$ of pentane and cooled to $-30{ }^{\circ} \mathrm{C}$ for $2 \mathrm{~d}$. Yellow crystals were isolated in $79 \%$ yield $(69.2$ $\left.\mathrm{mg}, 1.30 \times 10^{-4} \mathrm{~mol}\right) .{ }^{1} \mathrm{H} \mathrm{NMR}\left(d_{8}\right.$-THF): $\delta 6.56(\mathrm{t}, 2 \mathrm{H}, J=7.5$, $\operatorname{Ar} H), 6.34(\mathrm{~d}, 2 \mathrm{H}, J=7.5, \operatorname{Ar} H), 5.90(\mathrm{t}, 1 \mathrm{H}, J=7.5, \operatorname{Ar} H), 2.60(\mathrm{~s}$, $1 \mathrm{H}, \mathrm{CHPh}$ ), 1.71 (br m, 4H, DMPE), 1.62 (br m, 4H, DMPE), 1.45 (s, 12H, DMPE), 1.43 (s, 12H, DMPE), -18.9 (qn, 1H, $J=21, \mathrm{Ru} H$ ). ${ }^{13} \mathrm{C}\left\{{ }^{1} \mathrm{H}\right\}$ NMR $\left(\mathrm{C}_{6} \mathrm{D}_{6}\right.$, room temperature): $\delta 150.45$ (quat $C$ ), 144.65 (quat $C$ ), $129.15(\mathrm{CH}), 118.81(\mathrm{CH}), 113.22(\mathrm{CH}), 36.77(\mathrm{NCCHPh})$, 31.42 (m, DMPE), 22.24 (DMPE), 15.78 (DMPE). ${ }^{31} \mathrm{P}\left\{{ }^{1} \mathrm{H}\right\} \mathrm{NMR}\left(d_{8-}\right.$ THF): 48.15. IR (Nujol): 2120, 1922, 1580, 1547, 1485, 1461, 1421, $1374,1323,1289,1235,1198,1172,1150,1125,1093,1074,983$, 928, 888, 840, 793, 731, 703, 692, $643 \mathrm{~cm}^{-1}$. Anal. Calcd for $\mathrm{RuP}_{4-}$ $\mathrm{NC}_{20} \mathrm{H}_{39}$ : C, 46.33; H, 7.58; N, 2.70. Found: C, 46.53; H, 7.90; N, 2.61 .

trans-(DMPE) $)_{2} \mathbf{R u}(\mathrm{H})\left(\mathbf{N C C}\left(\mathrm{H}_{)} \mathbf{C}_{6} \mathbf{H}_{4} \mathrm{CF}_{3}\right)(\mathbf{9 b})\right.$. A vial was charged with trans-(DMPE) ${ }_{2} \mathrm{Ru}(\mathrm{H})\left(\mathrm{NH}_{2}\right)\left(76.6 \mathrm{mg}, 1.83 \times 10^{-4} \mathrm{~mol}\right)$ and 5 $\mathrm{mL}$ of toluene. To it was added a solution consisting of $4-(\alpha, \alpha, \alpha-$ trifluoromethyl)phenylacetonitrile) $\left(34.2 \mathrm{mg}, 1.85 \times 10^{-4} \mathrm{~mol}\right)$ and 5 $\mathrm{mL}$ of toluene. After $1 \mathrm{~d}$, the volatile materials were removed in vacuo. The purple residue was dissolved in $10 \mathrm{~mL}$ of THF and cooled to -30 ${ }^{\circ} \mathrm{C}$ for $2 \mathrm{~d}$. Light purple/green crystals were isolated in $74 \%$ yield $(81.8$ $\left.\mathrm{mg}, 1.35 \times 10^{-4} \mathrm{~mol}\right) .{ }^{1} \mathrm{H}$ NMR $\left(d_{8}\right.$-THF, $\left.203 \mathrm{~K}\right): \delta 6.80(\mathrm{~d}, 1 \mathrm{H}, J=$ 8.7, $\operatorname{Ar} H), 6.72(\mathrm{~d}, 1 \mathrm{H}, J=9.2, \operatorname{Ar} H), 6.42(\mathrm{~d}, 1 \mathrm{H}, J=8.7, \operatorname{Ar} H)$, $6.15(\mathrm{~d}, 1 \mathrm{H}, J=8.7, \operatorname{Ar} H$ ), 3.01 (s, $1 \mathrm{H}, \mathrm{NCCHAr}$ ), 1.69 (br m, 8H, DMPE), 1.44 (s, 24H, DMPE), -18.67 (qn, $1 \mathrm{H}, J=21.1$, RuH). ${ }^{13} \mathrm{C}-$ $\left\{{ }^{1} \mathrm{H}\right\}$ NMR ( $d_{8}$-THF, room temperature): $\delta 152.5$ (quat), 136.6 (quat), $127.9(\mathrm{CH}), 127.1(\mathrm{CH}), 124.2(\mathrm{CH}), 123.8(\mathrm{CH}), 38.47$ (NCCHAryl), $29.86(\mathrm{~m}), 20.28(\mathrm{~m}), 13.86 .{ }^{31} \mathrm{P}\left\{{ }^{1} \mathrm{H}\right\}$ NMR $\left(d_{8}\right.$-THF, room temperature): $\delta$ 47.67. IR (Nujol): 2134, 1943, 1594, 1531, 1512, 1461, 1420, 1393, 1379, 1308, 1234, 1214, 1177, 1143, 1100, 1067, 1049, 936, 912, 890, 841, 815, 796, 733, 705, $646 \mathrm{~cm}^{-1}$. Anal. Calcd for $\mathrm{RuP}_{4^{-}}$ 
$\mathrm{NC}_{21} \mathrm{~F}_{3} \mathrm{H}_{38}: \mathrm{C}, 43.01 ; \mathrm{H}, 6.53 ; \mathrm{N}, 2.39$. Found: $\mathrm{C}, 43.35 ; \mathrm{H}, 6.89 ; \mathrm{N}$, 2.69 .

trans-(DMPE) $)_{2} \mathbf{R u}(\mathbf{H})\left(\mathbf{C}_{4} \mathbf{H}_{5} \mathbf{O}\right)$ (10). A vial was charged with 79.3 $\mathrm{mg}\left(1.90 \times 10^{-4} \mathrm{~mol}\right)$ of trans-(DMPE $)_{2} \mathrm{Ru}(\mathrm{H})\left(\mathrm{NH}_{2}\right)$ and $5 \mathrm{~mL}$ of toluene. To it was added a solution consisting of cyclobutanone (13.8 $\mathrm{mg}, 1.97 \times 10^{-4} \mathrm{~mol}$ ) and $5 \mathrm{~mL}$ of toluene. After $1 \mathrm{~d}$, the volatile materials were removed in vacuo, and the residue was dissolved in 3 $\mathrm{mL}$ of ether. The solution was cooled to $-30^{\circ} \mathrm{C}$ for $3 \mathrm{~d}$ to give orange crystals in $59 \%$ yield $\left(52.8 \mathrm{mg}, 1.12 \times 10^{-4} \mathrm{~mol}\right) .{ }^{1} \mathrm{H}$ NMR $\left(\mathrm{THF}-d_{8}\right.$, room temperature): $\delta 2.83$ (br m, 1H), 2.76 (br m, 1H), 2.29 (br m, 1H), 1.87 (br m, 1H), 1.79 (br m, 1H), 1.46 (s, 24H, DMPE), 1.35 (s, $8 \mathrm{H}, \mathrm{DMP} E) .{ }^{13} \mathrm{C}\left\{{ }^{1} \mathrm{H}\right\}$ NMR (THF- $d_{8}$, room temperature): $\delta 212.67$ (CO), $41.84\left(\mathrm{CH}_{2} \mathrm{C}(\mathrm{O})\right), 40.47$ (qn, $\left.J_{\mathrm{CP}}=18.5, \mathrm{RuCH}\right), 31.73$ (br m, DMPE), 26.75 (br m, DMPE), $23.13\left(\mathrm{RuCHCH}_{2} \mathrm{C}(\mathrm{O})\right.$ ), 15.77 (br m, DMPE). ${ }^{13} \mathrm{P}\left\{{ }^{1} \mathrm{H}\right\}$ NMR (THF- $d_{8}$, room temperature): $\delta 39.77(\mathrm{~m}), 38.73$ (m). IR (Nujol): 1832, 1636, 1523, 1458, 1421, 1377, 1292, 1276, 1250, 1234, 1146, 1120, 1081, 1010, 936, 888, 839, 796, $721 \mathrm{~cm}^{-1}$. Anal. Calcd for $\mathrm{RuP}_{4} \mathrm{OC}_{16} \mathrm{H}_{38}$ : C, 40.76; H, 8.12. Found: C, 41.00; H, 8.42 .

trans-(DMPE $)_{2} \mathbf{R u}(\mathbf{H})\left(\mathbf{O C}_{6} \mathbf{H}_{5}\right)(\mathbf{1 1 b})$. A vial was charged with trans$(\mathrm{DMPE})_{2} \mathrm{Ru}(\mathrm{H})\left(\mathrm{NH}_{2}\right)\left(52.6 \mathrm{mg}, 1.26 \times 10^{-4}\right)$ and $10 \mathrm{~mL}$ of THF. To it was added a solution consisting of phenol $\left(12.7 \mathrm{mg}, 1.17 \times 10^{-4}\right.$ $\mathrm{mol}$ ) and $5 \mathrm{~mL}$ of THF. After allowing the resulting solution to stand for $1 \mathrm{~h}$ at $25^{\circ} \mathrm{C}$, the volatile materials were slowly removed $(4 \mathrm{~h})$ under reduced pressure. The white residue was dissolved in a minimal amount of toluene $(0.5 \mathrm{~mL})$, and $2 \mathrm{~mL}$ of pentane was layered onto this solution. The resulting solution was placed at $-30{ }^{\circ} \mathrm{C}$ for $2 \mathrm{~d}$ to produce white crystals of $\mathbf{1 1 b}\left(49 \%, 30.5 \mathrm{mg}, 6.17 \times 10^{-5} \mathrm{~mol}\right) .{ }^{1} \mathrm{H}$ NMR $\left(\mathrm{C}_{6} \mathrm{D}_{6}\right): \delta 7.34(\mathrm{t}, 2 \mathrm{H}, J=7.4), 6.61(\mathrm{t}, 1 \mathrm{H}, J=6.8), 6.42(\mathrm{~d}$, $2 \mathrm{H}, J=6.3), 1.64(\mathrm{~m}, 4 \mathrm{H}), 1.30(\mathrm{~s}, 12 \mathrm{H}), 1.24(\mathrm{~m}, 4 \mathrm{H}), 1.09(\mathrm{~s}, 12 \mathrm{H})$, -23.30 (qn, $1 \mathrm{H}, J=22.0$ ). ${ }^{31} \mathrm{P}\left\{{ }^{1} \mathrm{H}\right\}$ NMR $\left(\mathrm{C}_{6} \mathrm{D}_{6}\right): \delta$ 45.4. lit. ${ }^{30}{ }^{1} \mathrm{H}$ $\operatorname{NMR}\left(\mathrm{C}_{6} \mathrm{D}_{6}\right): \delta 7.35(\mathrm{t}, 2 \mathrm{H}, J=7.8), 6.62(\mathrm{t}, 1 \mathrm{H}, J=6.8), 6.43(\mathrm{~d}$, $2 \mathrm{H}, J=7.6), 1.65(\mathrm{~m}, 4 \mathrm{H}), 1.30(\mathrm{~s}, 12 \mathrm{H}), 1.23(\mathrm{~m}, 4 \mathrm{H}), 1.09(\mathrm{~s}, 12 \mathrm{H})$, -23.3 (qn, $1 \mathrm{H}, J=21.8) .{ }^{31} \mathrm{P}\left\{{ }^{1} \mathrm{H}\right\} \operatorname{NMR}\left(\mathrm{C}_{6} \mathrm{D}_{6}\right): \delta 45.4$.

trans-(DMPE) $)_{2} \mathbf{R u}(\mathrm{H})\left(\mathrm{OC}_{6} \mathrm{H}_{4} \mathrm{Me}\right) \quad(11 \mathrm{c})$. trans-(DMPE $)_{2} \mathrm{Ru}(\mathrm{H})-$ $\left(\mathrm{NH}_{2}\right)\left(57.3 \mathrm{mg}, 1.37 \times 10^{-4} \mathrm{~mol}\right)$ was dissolved in $10 \mathrm{~mL}$ of THF. To this was added a solution consisting $p$-cresol $\left(12.7 \mathrm{mg}, 1.35 \times 10^{-4}\right.$ mol) and $5 \mathrm{~mL}$ of THF. The resulting solution was allowed to stand for $1 \mathrm{~h}$ at $25^{\circ} \mathrm{C}$, after which the volatile materials were slowly removed $(4 \mathrm{~h})$ under reduced pressure. The white residue was dissolved in a minimal amount of toluene $(0.5 \mathrm{~mL})$, and the resulting solution was layered with $2 \mathrm{~mL}$ of pentane and cooled to $-30^{\circ} \mathrm{C}$ for $2 \mathrm{~d}$ to give white crystals of $11 \mathrm{c}\left(57 \%, 39.2 \mathrm{mg}, 7.70 \times 10^{-5} \mathrm{~mol}\right) .{ }^{1} \mathrm{H}$ NMR $\left(\mathrm{C}_{6} \mathrm{D}_{6}\right): \delta 7.11(\mathrm{~d}, 2 \mathrm{H}, J=8.0), 6.36(\mathrm{~d}, 2 \mathrm{H}, J=7.9), 2.41(\mathrm{~s}, 3 \mathrm{H})$, $1.66(\mathrm{~m}, 4 \mathrm{H}), 1.32(\mathrm{~s}, 12 \mathrm{H}), 1.25(\mathrm{~m}, 4 \mathrm{H}), 1.10(\mathrm{~s}, 12 \mathrm{H}),-23.19(\mathrm{qn}$, $1 \mathrm{H}, J=20.0) .{ }^{31} \mathrm{P}\left\{{ }^{1} \mathrm{H}\right\} \mathrm{NMR}\left(\mathrm{C}_{6} \mathrm{D}_{6}\right): \delta 45.6$. lit. ${ }^{37}{ }^{1} \mathrm{H}$ NMR $\left(\mathrm{C}_{6} \mathrm{D}_{6}\right)$ : $\delta 7.11(\mathrm{~d}, 2 \mathrm{H}, J=8.1), 6.38(\mathrm{~d}, 2 \mathrm{H}, J=7.7), 2.40(\mathrm{~s}, 3 \mathrm{H}), 1.66(\mathrm{~m}$, $4 \mathrm{H}), 1.32$ (s, 12H), $1.26(\mathrm{~m}, 4 \mathrm{H}), 1.00(\mathrm{~s}, 12 \mathrm{H}),-23.20$ (qn, 1H, $J=$ 21.8). ${ }^{31} \mathrm{P}\left\{{ }^{1} \mathrm{H}\right\}$ NMR $\left(\mathrm{C}_{6} \mathrm{D}_{6}\right): \delta 45.5$.

trans-(DMPE) $)_{2} \mathbf{R u}(\mathbf{H})\left(\mathbf{N H C}_{6} \mathbf{H}_{5}\right)$ (12). trans-(DMPE) $)_{2} \mathrm{Ru}(\mathrm{H})\left(\mathrm{NH}_{2}\right)$ (134 mg, $3.21 \times 10^{-4} \mathrm{~mol}$ ) was dissolved in $3 \mathrm{~mL}$ of THF. To it was added a solution consisting of aniline $\left(29.8 \mathrm{mg}, 3.20 \times 10^{-4} \mathrm{~mol}\right)$ and $1 \mathrm{~mL}$ of THF. The solution was allowed to stand for $1.5 \mathrm{~d}$, after which the volatile materials were removed in vacuo. The yellow residue was dissolved in a minimal amount of toluene $(1 \mathrm{~mL})$. After layering with $2 \mathrm{~mL}$ of pentane, the solution was cooled to $-30{ }^{\circ} \mathrm{C}$ for $2 \mathrm{~d}$ to give pale-yellow crystals of $\mathbf{1 1}$ in $57 \%$ yield $\left(89.9 \mathrm{mg}, 1.82 \times 10^{-4} \mathrm{~mol}\right)$. ${ }^{1} \mathrm{H}$ NMR $\left(\mathrm{C}_{6} \mathrm{D}_{6}\right): \delta 7.20(\mathrm{t}, 2 \mathrm{H}, J=6.9), 6.35(\mathrm{t}, 1 \mathrm{H}, J=6.8), 6.22$ $(\mathrm{d}, 2 \mathrm{H}, J=7.1), 1.43(\mathrm{~m}, 4 \mathrm{H}), 1.27(\mathrm{~s}, 12 \mathrm{H}), 1.19(\mathrm{~m}, 4 \mathrm{H}), 1.11(\mathrm{~s}$, $12 \mathrm{H}),-19.13$ (qn, $1 \mathrm{H}, J=23.0) .{ }^{31} \mathrm{P}\left\{{ }^{1} \mathrm{H}\right\} \mathrm{NMR}\left(\mathrm{C}_{6} \mathrm{D}_{6}\right): \delta 44.6$. lit. $^{37}$ ${ }^{1} \mathrm{H}$ NMR $\left(\mathrm{C}_{6} \mathrm{D}_{6}\right): \delta 7.22(\mathrm{t}, 2 \mathrm{H}, J=7.4), 6.38(\mathrm{~m}, 1 \mathrm{H}), 6.24(\mathrm{~d}, 2 \mathrm{H}$, $J=7.8), 1.42(\mathrm{~m}, 4 \mathrm{H}), 1.27(\mathrm{~s}, 12 \mathrm{H}), 1.16(\mathrm{~m}, 4 \mathrm{H}), 1.10(\mathrm{~s}, 12 \mathrm{H})$, -19.13 (qn, $1 \mathrm{H}, J=22.9) .{ }^{31} \mathrm{P}\left\{{ }^{1} \mathrm{H}\right\}$ NMR $\left(\mathrm{C}_{6} \mathrm{D}_{6}\right): \delta 44.5$.

trans-(DMPE) $)_{2} \mathbf{R u}(\mathbf{H})\left(\mathbf{C H}_{2} \mathbf{P h}\right)(\mathbf{1 3})$. A vial was charged with trans$(\mathrm{DMPE})_{2} \mathrm{Ru}(\mathrm{H})(\mathrm{Cl})\left(177.7 \mathrm{mg}, 4.06 \times 10^{-4} \mathrm{~mol}\right)$ and $10 \mathrm{~mL}$ of THF. To it was added a $1.0 \mathrm{M}$ hexanes solution of benzylmagnesium chloride $\left(4.10 \mathrm{~mL}, 4.10 \times 10^{-4} \mathrm{~mol}\right)$ via a syringe. After $3 \mathrm{~h}$ at $25^{\circ} \mathrm{C}$, the volatile materials were removed under reduced pressure. Pentane (2 $\mathrm{mL}$ ) was added and evaporated to remove residual THF, after which time the crude product was extracted with THF $(10 \mathrm{~mL})$, and the resulting solution was filtered through glass fiber. Recrystallization from pentane $(5 \mathrm{~mL})$ resulted in yellow crystals of $\mathbf{1 4}(69.9 \mathrm{mg}, 1.42 \times$ $\left.10^{-4} \mathrm{~mol}, 35 \%\right) .{ }^{1} \mathrm{H}$ NMR $\left(\mathrm{THF}-d_{8}\right): \delta 6.69(\mathrm{~d}, 2 \mathrm{H}, J=7.6, \mathrm{Ar} H)$, $6.64(\mathrm{t}, 2 \mathrm{H}, J=6.8, \operatorname{Ar} H), 6.35(\mathrm{t}, 1 \mathrm{H}, J=6.8, \operatorname{Ar} H), 1.6(\mathrm{br}, 2 \mathrm{H}$, $\mathrm{RuCH}_{2} \mathrm{Ph}$ ), 1.5 (br m, 4H, DMPE), 1.4 (br m, 4H, DMPE), 1.4 (m, 12H, DMPE), 1.2 (m, 12H, DMPE), -15.40 (qn, $1 \mathrm{H}, J=22.5, \mathrm{Ru} H$ ). ${ }^{13} \mathrm{C}\left\{{ }^{1} \mathrm{H}\right\}$ NMR $\left(\mathrm{C}_{6} \mathrm{D}_{6}\right): \delta 165.54$ (quat), $128.77(\mathrm{CH}), 127.88(\mathrm{CH})$, $125.90(\mathrm{CH}), 31.67$ (DMPE), 27.03 (DMPE), 15.42 (DMPE), 15.76 (qn, $\left.J_{\mathrm{CP}}=20, \mathrm{Ru}-\mathrm{CH}_{2} \mathrm{Ph}\right) .{ }^{31} \mathrm{P}\left\{{ }^{1} \mathrm{H}\right\} \mathrm{NMR}\left(\mathrm{THF}-d_{8}\right): \delta 48.86 . \mathrm{IR}$ (Nujol): 1786, 1586, 1565, 1469, 1416, 1378, 1291, 1274, 1231, 1210, 1169, 1119, 1073, 1042, 1023, 1010, 973, 925, 885, 835, 790, 751, 719, 694, 644, $633 \mathrm{~cm}^{-1}$. Anal. Calcd for $\mathrm{C}_{19} \mathrm{H}_{40} \mathrm{P}_{4} \mathrm{Ru}: \mathrm{C}, 46.24 ; \mathrm{H}$, 8.17. Found: C, $45.90 ; \mathrm{H}, 8.27$.

Oxidation of 1,4-Cyclohexadiene or Anthracene with Amido Complex 1 or Hydroxo Complex 2: General Procedure. In a typical experiment, $0.5 \mathrm{~mL}$ of a THF- $d_{8}$ solution was prepared containing trans$(\mathrm{DMPE})_{2} \mathrm{Ru}(\mathrm{H})\left(\mathrm{NH}_{2}\right)\left(10 \mathrm{mg}, 2.4 \times 10^{-5} \mathrm{~mol}\right), 9,10$-dihydroanthracene (4.4 mg, $2.4 \times 10^{-5} \mathrm{~mol}$ ), and 1,3,5-trimethoxybenzene (internal standard, $\left.3.4 \mathrm{mg}, 2.0 \times 10^{-5} \mathrm{~mol}\right)$. The reactions were monitored by ${ }^{1} \mathrm{H}$ and ${ }^{31} \mathrm{P}\left\{{ }^{1} \mathrm{H}\right\}$ NMR spectroscopy. The identities of (DMPE) ${ }_{2} \mathrm{Ru}(\mathrm{H})_{2}$ and anthracene were ascertained by comparison of their NMR spectra with those of authentic samples. Anthracene was also identified by comparison of its GC retention time with that of an authentic sample.

H/D Exchange Experiments: Typical Procedure. An NMR tube was charged with trans-(DMPE) ${ }_{2} \mathrm{Ru}(\mathrm{H})\left(\mathrm{NH}_{2}\right)\left(12 \mathrm{mg}, 2.9 \times 10^{-5} \mathrm{~mol}\right)$, triphenylmethane $\left(6.5 \mathrm{mg}, 2.7 \times 10^{-5} \mathrm{~mol}\right), 1,3,5$-trimethoxybenzene (internal standard, $4.2 \mathrm{mg}, 2.5 \times 10^{-5} \mathrm{~mol}$ ), and $0.5 \mathrm{~mL}$ of toluene- $d_{8}$. After $4 \mathrm{~h}$, a one-pulse ${ }^{1} \mathrm{H}$ NMR spectrum was acquired, and the proton resonances of triphenylmethane and toluene- $d_{8}$ were integrated against the proton resonances of the internal standard 1,3,5-trimethoxybenzene. The volatile materials were removed in vacuo, and the residue was dissolved in $0.5 \mathrm{~mL}$ of benzene (protiated). ${ }^{2} \mathrm{H}$ NMR $\left(\mathrm{C}_{6} \mathrm{H}_{6}\right): \delta 5.41$ (s, $\mathrm{Ph}_{3} \mathrm{C}-H$ ), 1.52 (br s, DMPE), 1.34 (br s, DMPE), 1.29 (s, DMPE).

Equilibrium Studies of the Reaction between trans-(DMPE) $)_{2} \mathrm{Ru}-$ $(\mathbf{H})(\mathrm{OH})$ and Fluorene: General Procedure. In a typical experiment, a stock solution was made by charging a $2.00 \mathrm{~mL}$ volumetric flask with trans-(DMPE) ${ }_{2} \mathrm{Ru}(\mathrm{H})(\mathrm{OH})\left(39.0 \mathrm{mg}, 9.30 \times 10^{-5} \mathrm{~mol}, 4.65 \times\right.$ $\left.10^{-2} \mathrm{M}\right)$, fluorene $\left(11.6 \mathrm{mg}, 6.90 \times 10^{-5} \mathrm{~mol}, 3.45 \times 10^{-2} \mathrm{M}\right), 1,3,5-$ trimethoxybenzene (internal standard, $10.4 \mathrm{mg}, 6.18 \times 10^{-5} \mathrm{~mol}, 3.09$ $\times 10^{-2} \mathrm{M}$ ), and freshly distilled THF- $d_{8}$ until the volume totaled 2.00 $\mathrm{mL}$. The solution was stored in a Teflon-sealed vial at $-30^{\circ} \mathrm{C}$. A 0.5 $\mathrm{mL}$ aliquot was transferred to an NMR tube with a Teflon-seal and inserted into an NMR probe that had been precalibrated with a neat ethylene glycol sample to $25.0{ }^{\circ} \mathrm{C}$. After $15 \mathrm{~min}$, a 16-pulse spectrum using a $60 \mathrm{~s}$ delay to allow for complete proton relaxation was acquired.

Equilibrium Studies of the Reaction between trans-(DMPE) ${ }_{2} \mathrm{Ru}$ $(\mathbf{H})\left(\mathbf{N H}_{2}\right)$ and Triphenylmethane: General Procedure. In a typical experiment, a stock solution was made by charging a $5.00 \mathrm{~mL}$ volumetric flask with trans-(DMPE) $)_{2} \mathrm{Ru}(\mathrm{H})\left(\mathrm{NH}_{2}\right)(32.3 \mathrm{mg}, 7.73 \times$ $\left.10^{-5} \mathrm{~mol}, 1.55 \times 10^{-2} \mathrm{M}\right), 1,3,5$-trimethoxybenzene (internal standard, $\left.15.0 \mathrm{mg}, 8.92 \times 10^{-5} \mathrm{~mol}, 1.78 \times 10^{-2} \mathrm{M}\right)$, and freshly distilled THF$d_{8}$ until the volume totaled $5.00 \mathrm{~mL}$ (stock solution 1 ). The solution was stored in a Teflon-sealed vial at $-30{ }^{\circ} \mathrm{C}$. A $1.00 \mathrm{~mL}$ volumetric flask was charged with triphenylmethane $\left(13.1 \mathrm{mg}, 5.36 \times 10^{-5} \mathrm{~mol}\right.$, $\left.5.36 \times 10^{-2} \mathrm{M}\right)$ and enough stock solution to bring the total volume to $1.00 \mathrm{~mL}$. A $0.5 \mathrm{~mL}$ aliquot was transferred to an NMR tube with a Teflon-seal. The tube was inserted into an NMR probe, precooled to $250.2 \mathrm{~K}$. After $15 \mathrm{~min}$, a one-pulse spectrum was acquired. Spectra were acquired at four more temperatures after allowing for a $15 \mathrm{~min}$ equilibration to the desired temperature. ${ }^{1} \mathrm{H}$ NMR $\left(d_{8}\right.$-THF, $\left.202 \mathrm{~K}\right): \delta$ $7.35(\mathrm{~d}, 6 \mathrm{H}, J=8.0, \operatorname{Ar} H), 6.50(\mathrm{t}, 6 \mathrm{H}, J=7.5, \operatorname{Ar} H), 5.94(\mathrm{t}, 3 \mathrm{H}, J$ $=7, \operatorname{Ar} H$ ), 1.65 (br m, 4H, DMPE), 1.54 (br m, 4H, DMPE), 1.36 (s, 
12H, DMPE), 1.29 (s, 12H, DMPE), 0.08 (br s, 3H, NH $H_{3}$ ), -19.0 (qn, $1 \mathrm{H}, J=20 \mathrm{H}, \mathrm{Ru} H) .{ }^{13} \mathrm{C}\left\{{ }^{1} \mathrm{H}\right\} \mathrm{NMR}\left(d_{8}\right.$-THF, $\left.202 \mathrm{~K}\right): \delta 150.0$ (quat), $128.4(\mathrm{CH}), 124.2(\mathrm{CH}), 113.3(\mathrm{CH}), 91.4$ (quat), $31.3(\mathrm{~m}, \mathrm{DMPE})$, 22.9 (m, DMPE), 14.0 (m, DMPE). ${ }^{31} \mathrm{P}\left\{{ }^{1} \mathrm{H}\right\}$ NMR ( $d_{8}$-THF, $\left.202 \mathrm{~K}\right)$ : $\delta 45.1$.

X-ray Structure Determinations of 4a, 4e, 9b, and 10: General Procedure. Crystals were mounted on a quartz fiber using Paratone $\mathrm{N}$ hydrocarbon oil and were cooled by a nitrogen-flow low-temperature apparatus. Crystal quality was evaluated via measurements of intensities and inspection of peak scans. All measurements were made on a Siemens SMART (Siemens Industrial Automation, Inc.) diffractometer with a CCD area detector using graphite monochromated Mo $\mathrm{K} \alpha$ radiation and an exposure time of $10 \mathrm{~s} /$ frame. The raw data were integrated by the program SAINT (SAX Area-Detector Integration Program) and were corrected for Lorentz and polarization effects. Data were analyzed for agreement and possible adsorption using XPREP. ${ }^{72}$ Empirical adsorption corrections were based on comparisons of redundant and equivalent reflections as applied using XPREP or SADABS. ${ }^{73}$ The structures were solved by direct methods and expanded using Fourier techniques. Except as noted, all non-hydrogen atoms were refined anisotropically, and hydrogen atoms were included as fixed contributions but not refined. The function minimized in the full-matrix least-squares refinement was $\sum w\left(\left|F_{\mathrm{o}}\right|-\left|F_{\mathrm{c}}\right|\right)^{2}$. The weighting scheme was based on counting statistics and included a factor to downweight the intense reflections.

For 4a. Orange platelike crystals were obtained by slowly cooling a solution of $\mathbf{4 a}$ in THF and pentane to $-30^{\circ} \mathrm{C}$. The systematic absences of $h 01: h \neq 2 n$ and $0 k 0 \neq 2 n$ uniquely determined the space group to be $P 2{ }_{1} / a$ (No. 14). The hydrides (H71 and H72) were located in the difference electron density map. Their positions were refined, but their isotropic thermal parameters were held fixed.

For 4e. Colorless crystals were obtained by the slow diffusion of pentane into a concentrated THF solution of $4 \mathrm{e}$ at $-30{ }^{\circ} \mathrm{C}$. The systematic absences of $h 01: h+1 \neq 2 n$ and $0 k 0: k \neq 2 n$ uniquely determined the space group to be $P 2_{1} / n$ (No. 14). The hydride and ammonia hydrogens on both ruthenium complexes were located from a difference Fourier map and included with refined coordinates and a

(72) XPREP, version 5.03; Part of the SHELXTL Crystal Structure; Determination Siemens Industrial Automation, Inc.: Madison, WI, 1995.

(73) SADABS: Siemens Area Detector ABSorption correction program; George Sheldrick, 1996. Advance copy, private communication. fixed $B_{\text {iso }}\left(B_{\text {iso }}=3.32\right)$. Their positions were refined, and their isotropic thermal parameters were held fixed.

For $9 \mathrm{~b}$. Golden platelike crystals were obtained by the slow cooling of a THF solution of $\mathbf{9 b}$ to $-30{ }^{\circ} \mathrm{C}$. On the basis of the systematic absences of $0 k 1: k+1 \neq 2 n$ and $h k 0: h \neq 2 n$, packing considerations, a statistical analysis of intensity distribution, and the successful solution and refinement of the structure, the space group was determined to be Pnma (No. 62). Attempts to refine the carbon atoms anisotropically led to unreasonable values for the components of the anisotropic displacement parameters and a low data-to-parameter ratio. The hydride (H1) was located in the difference electron density map. The hydrogen atom coordinates were refined isotropically.

For 10. Colorless blocklike crystals were grown by slowly cooling a concentrated diethyl ether solution of 10 to $-30{ }^{\circ} \mathrm{C}$. On the basis of a statistical analysis of intensity distribution, and the successful solution and refinement of the structure, the space group was determined to be $P 1$ (No. 2). The hydride ligands and the hydrogen atoms of the $\alpha$ carbons $\mathrm{C} 13$ and $\mathrm{C} 29$ were located in the difference electron density map and their positions refined with fixed thermal parameters.

Acknowledgment. The authors are grateful for financial support from the National Science Foundation (grant no. CHE0094349). M.W.B. acknowledges the Dow Chemical Co. for support. We would like to thank Dr. F. J. Hollander, Dr. Dana Caulder, and Dr. Allen Oliver for determining the solid-state structures of 4a, 9, 10, and 4e. We are very grateful to Prof. Kenneth Wiberg and the Yale chemistry department for allowing S.S. to perform calculations on their computers (NIH); the work in the Wiberg laboratory was supported by NIH grant GM53708. We would also like to thank Prof. Andrew Streitwieser for helpful discussions on acidity questions.

Supporting Information Available: Tables giving details of the data collection, refinement, atomic coordinates, thermal parameters, bond lengths, and bond angles for complexes $\mathbf{4 a}$, 9, 10, and 4e. In addition, the experimental used in the calculations along with tables of computational data including the absolute energies, ZPEs, and Cartesian coordinates for all calculated species (PDF). This material is available free of charge via the Internet at http://pubs.acs.org.

JA011876O 